Article

\title{
Non-Destructive Study of the Microstructural Effects of Sodium and Magnesium Sulphate Attack on Mortars Containing Silica Fume Using Impedance Spectroscopy
}

\author{
Mark Williams ${ }^{1}$, José Marcos Ortega ${ }^{2, *}$, Isidro Sánchez ${ }^{2}$, Marta Cabeza ${ }^{3}$ \\ and Miguel Ángel Climent ${ }^{2}$ \\ 1 Engineeria, 7 Ridgmount Street, London WC1E 7AE, UK; markmboro@gmail.com \\ 2 Departamento de Ingeniería Civil, Universidad de Alicante, Ap. Correos 99, 03080 Alicante, Spain; \\ isidro.sanchez@ua.es (I.S.); ma.climent@ua.es (M.Á.C.) \\ 3 Grupo ENCOMAT, Escola de Enxeñaría Industrial, Universidade de Vigo, Campus Universitario, \\ 36310 Vigo, Spain; mcabeza@uvigo.es \\ * Correspondence: jm.ortega@ua.es; Tel.: +34-96-5903-400 (ext. 1167)
}

Academic Editor: Stefano Invernizzi

Received: 17 May 2017; Accepted: 20 June 2017; Published: 23 June 2017

\begin{abstract}
The microstructural effects of exposure to a $15 \%$ magnesium sulphate, $15 \%$ sodium sulphate, and mixed solutions were observed in mortars with and without silica fume, using the non-destructive impedance spectroscopy technique. The non-destructive "Wenner" resistivity test and the classical mercury intrusion porosimetry were used as contrast techniques. The compressive strength of the mortars was also studied. In view of the results obtained, impedance spectroscopy was the most sensitive technique for detecting changes in the porous network of the studied mortars. The addition of silica fume results in a more refined microstructure and a higher compressive strength in mortars exposed to aggressive sulphate solutions.
\end{abstract}

Keywords: Impedance spectroscopy; sulphate attack; microstructure; silica fume; magnesium

\section{Introduction}

Currently, the use of non-destructive techniques for characterizing the microstructure of cement-based materials has become an important research field [1-7]. Among these techniques, impedance spectroscopy has been greatly developed during the last few years. Other authors have successfully studied cement-based materials using this non-destructive technique in order to observe the formation of Friedel's salt [8], study the effects of curing conditions [9] and pozzolanic additions [10], determine the non-steady state chloride diffusion coefficient [11], and the distribution of moisture [12]. However, the use of impedance spectroscopy to study the effects of sulphate attack on the microstructure of cement-based materials in general has hardly been considered [13]. The effect of sulphate attack is commonly studied in terms of expansion [14], mechanical strength loss [15] and mass variations [16], and the use of active additions to reduce sensitivity to sulphate attack. Microstructural changes are observed mainly by scanning electron microscopy (SEM) analysis [14], mercury intrusion porosimetry (MIP), thermogravimetry (TG), and X-ray diffraction (XRD). Little attention has been paid to the non-destructive study of the microstructural origins of changes in these properties, and especially in the case of the partial replacement of cement with silica fume, used as an addition to improve the sulphate resistance of cements [17-19] (among other positive effects).

While both the deleterious effects of sulphate attack on Portland cement based materials, and the positive effect of silica fume addition on resistance to this phenomenon are well known $[17,19]$, 
relatively less attention has been paid to the effect of the associated cation. The classic deleterious effects of sulphate attack (ettringite and gypsum formation) are associated with the sulphate anion. It has been suggested that among the most typical associated cations, calcium and sodium are innocuous, while magnesium is aggressive [20]. On one hand, the chemical reactions produced by the sodium sulphate attack are shown in Equations (1) and (2). The reaction shown in Equation (2) produces the formation of expansive ettringite crystals.

$$
\begin{gathered}
\mathrm{Ca}(\mathrm{OH})_{2}+\mathrm{Na}_{2} \mathrm{SO}_{4}+2 \mathrm{H}_{2} \mathrm{O} \rightarrow \mathrm{CaSO}_{4} \cdot 2 \mathrm{H}_{2} \mathrm{O}+2 \mathrm{NaOH} \\
3 \mathrm{CaO} \cdot \mathrm{Al}_{2} \mathrm{O}_{3}+3 \mathrm{CaSO}_{4} \cdot 2 \mathrm{H}_{2} \mathrm{O}+26 \mathrm{H}_{2} \mathrm{O} \rightarrow 3 \mathrm{CaO} \cdot \mathrm{Al}_{2} \mathrm{O}_{3} \cdot 3 \mathrm{CaSO}_{4} \cdot 32 \mathrm{H}_{2} \mathrm{O}
\end{gathered}
$$

On the other hand, the chemical reactions produced by the magnesium ion are shown in Equations (3) and (4). The reaction shown in Equation (3) results in the formation of magnesium hydroxide, or brucite, and is not greatly deleterious as calcium hydroxide does not contribute much to the strength of the hardened cement paste. The reaction shown in Equation (4) is referred to as decalcification henceforth, and results in a severe loss of compressive strength due to the conversion of conglomerate calcium silica hydrate gels into non-conglomerate magnesium silica hydrates [21-23].

$$
\begin{gathered}
\mathrm{Mg}^{2+}+\mathrm{Ca}(\mathrm{OH})_{2} \rightarrow \mathrm{Mg}(\mathrm{OH})_{2}+\mathrm{Ca}^{2+} \\
\mathrm{Mg}^{2+}+\mathrm{C}-\mathrm{S}-\mathrm{H} \rightarrow \mathrm{M}-\mathrm{S}-\mathrm{H}+\mathrm{Ca}^{2+}
\end{gathered}
$$

In addition, several authors have observed that the performance of mortars and concretes containing silica fume is worse than those without when exposed to magnesium sulphate solutions $[18,19,22-26]$. It has been suggested that due to the lower availability of calcium hydroxide, the reaction shown in Equation (3) does not take place to the same extent. It has been suggested that this reaction is preferential and leads to a lower availability of magnesium ions for the second, more damaging decalcification reaction shown in Equation (4) [23]. The formation of a double layer of brucite and gypsum has been observed [19], and it has been suggested that this forms a barrier, reducing the permeability of the cement paste [14,27].

While the effects of reactions involving the sulphate anion have been extensively studied, the microstructural changes produced in the pore network have received less attention, especially in terms of porosity and permeability related values. These parameters are important as they affect the service properties of structures, affecting the mechanical strength of concrete itself, as well as increasing the risk of corrosion of embedded reinforcement bars, for example by affecting the resistivity of the concrete or the ease of chloride ion ingress and promoting the easier ingress of sulphate salts. Many consider the corrosion of reinforcement bars to be the most important threat to real reinforced concrete structures [20]. Some authors have observed that at early ages, the formation of reaction products actually decreases the porosity due to the formation of reaction products that may be accommodated within the hardened cement's pore structure $[14,27,28]$. Similar microstructural changes have been observed during chloride migration experiments through concrete [29]. However, it appears that no current literature has considered the effect on electrical resistivity.

As such, the main objective of this research is to investigate the use of the non-destructive impedance spectroscopy technique in studying the aforementioned effects caused by sulphate attack on the microstructure of mortars with different contents of silica fume, compared to mortars containing ordinary Portland cement only. In order to check the validity of the impedance spectroscopy results, they have been contrasted with those results obtained using the more well-known and non-destructive "Wenner" resistivity test. The use of non-destructive techniques could allow for early detection of sulphate attack in concrete structures, with the consequence of being able to intervene at an early stage, avoiding possible disasters and the economic cost of repairs at an advanced stage of the attack. A classical technique, mercury intrusion porosimetry, has also been used as a contrast technique in this study. Finally, the compressive strength of mortars has been determined, in order to check the 
relationship between this property and the microstructural changes observed. In addition, compressive strength is very commonly used in the literature $[19,25,30]$ (as mentioned previously), for analyzing the effect of sulphate media on the behaviour of cement-based materials.

\section{Materials and Methods}

\subsection{Sample Preparation and Curing}

The tests were performed in mortars with different percentages of silica fume. The cement used was a high early strength type, designated CEM I $42.5 \mathrm{R}$ according to the Spanish and European standard UNE-EN 197-1 [31]. The silica fume used was undensified, with a cumulative volume of particles under $1 \mu \mathrm{m}$ of $90.78 \%$ and an average particle diameter of $0.67 \mu \mathrm{m}$. The chemical compositions of the cement and silica fume are shown in Table 1. For all the mortars, the water to cement ratio was 0.5 and the aggregate to cement ratio was 3:1. Fine aggregate was used according to the standard UNE-EN 196-1 [32]. Three types of mortars were prepared. One type consisted of mortars without added silica fume $(0 \%$ silica fume mortars hereafter), which were taken as a reference for behaviour. For the other mortars, $5 \%$ and $10 \%$ of cement was replaced with silica fume-referred to as $5 \%$ silica fume and $10 \%$ silica fume mortars (respectively) from now on.

Different types of specimens were prepared for the different test methods. On one hand, two kinds of cylindrical specimens were prepared. These were cast in moulds of either $10 \mathrm{~cm}$ diameter and $15 \mathrm{~cm}$ height, or $7.5 \mathrm{~cm}$ diameter and $30 \mathrm{~cm}$ height, respectively. On the other hand, $4 \times 4 \times 16 \mathrm{~cm}$ prismatic specimens were also prepared [32]. All the samples were cured for 7 days in a temperature and humidity controlled chamber at $20{ }^{\circ} \mathrm{C}$ and $95 \%$ relative humidity $(\mathrm{RH})$, and following this period were de-moulded and introduced into the corresponding sulphate solution. Before being exposed to the aggressive media, the 15-cm height cylindrical samples were cut to obtain approximately $2 \mathrm{~cm}$ thick discs, and the prismatic specimens were also cut in three equal parts with dimensions of $4 \times 4 \times$ $5.3 \mathrm{~cm}$. The tests were performed at different ages, up to 90 days of exposure to the sulphate solutions.

Table 1. Chemical composition of the cement and silica fume.

\begin{tabular}{ccc}
\hline Compound & CEM I 42.5R (\%) & Silica Fume (\%) \\
\hline $\mathrm{CaO}$ & 64.5 & 0.4 \\
$\mathrm{SiO}_{2}$ & 20.0 & 94.1 \\
$\mathrm{Al}_{2} \mathrm{O}_{3}$ & 5.7 & 0.3 \\
$\mathrm{Fe}_{2} \mathrm{O}_{3}$ & 2.5 & 0.1 \\
$\mathrm{SO}_{3}$ & 3.2 & 0.1 \\
$\mathrm{MgO}_{\mathrm{Na}}$ & 0.9 & 0.3 \\
$\mathrm{Na}_{2} \mathrm{O}$ & 0.1 & 0.6 \\
$\mathrm{~K}_{2} \mathrm{O}$ & 1.0 & 0.6 \\
\hline
\end{tabular}

\subsection{Sulphate Solutions}

The mortars were immersed in three different aggressive sulphate solutions, denominated according to the percentage by weight of the dissolved magnesium and sodium sulphates. The first solution contained $15 \%$ by weight of reagent grade anhydrous magnesium sulphate $\left(\mathrm{MgSO}_{4}\right)$. The second solution contained $15 \%$ by weight of reagent grade anhydrous sodium sulphate $\left(\mathrm{Na}_{2} \mathrm{SO}_{4}\right)$. Finally, a mixed sulphate solution was also studied, containing $7.5 \%$ magnesium sulphate and $7.5 \%$ sodium sulphate by weight. The content in the aggressive ions of interest is shown in Table 2. The $15 \%$ sulphate concentration has been selected in order to accelerate the attack of this aggressive ion and to observe its deleterious effects at relatively early exposure ages. The solutions were changed once during the test period (after 45 days exposure) to maintain a high enough concentration of sulphates in the solutions. The volume of solutions was approximately 4 times the volume of the samples, as recommend by the ASTM C 1012-04 standard [33]. 
Table 2. Content in aggressive ions and the ratio of magnesium to sulphate ions in the sulphate solutions used.

\begin{tabular}{ccccccc}
\hline Solution Name & $\mathbf{M g}^{2+}(\mathrm{g} / \mathrm{L})$ & $\mathbf{S O}_{4}{ }^{2-}(\mathrm{g} / \mathrm{L})$ & $\begin{array}{c}\text { Mass Ratio } \\
\mathbf{M g}^{2+} / \mathbf{S O}_{4}{ }^{2-}\end{array}$ & $\begin{array}{c}\mathbf{M g}^{2+} \\
(\mathbf{m o l} / \mathbf{L})\end{array}$ & $\begin{array}{c}\mathbf{S O}_{4}{ }^{2-} \\
(\mathbf{m o l} / \mathbf{L})\end{array}$ & $\begin{array}{c}\text { Molar Ratio } \\
\mathbf{M g}^{2+} / \mathbf{S O}_{4}{ }^{2-}\end{array}$ \\
\hline $15 \% \mathrm{MgSO}_{4}$ & 30.290 & 119.710 & 0.253 & 1.246 & 1.246 & 1.000 \\
$15 \% \mathrm{Na}_{2} \mathrm{SO}_{4}$ & 0 & 101.442 & 0 & 0 & 1.056 & 0 \\
$7.5 \% \mathrm{MgSO}_{4}+7.5 \%$ & 15.145 & 110.576 & 0.136 & 0.621 & 1.151 & 0.539 \\
$\mathrm{Na}_{2} \mathrm{SO}_{4}$ & & & & & \\
\hline
\end{tabular}

\subsection{Impedance Spectroscopy}

Potential was applied to saturated $2 \mathrm{~cm}$-height cylindrical samples immediately after their removal from the solution and superficial drying. The equipment used to apply the potential was an impedance analyzer capable of capacitance measurements in the $10^{-14}-0.1 \mathrm{~F}$ range, with a maximum resolution of $1 \times 10^{-15} \mathrm{~F}$. Circular copper electrodes with a flexible graphite contact surface and a diameter of $8 \mathrm{~cm}$ were used, and measurements were taken over a frequency range of $100 \mathrm{~Hz}$ to $100 \mathrm{MHz}$. Both contacting and non-contacting methods were used. For the non-contacting measurements, rectangular plastic sheets were used to insulate the sample. The equivalent circuits used were those proposed by Cabeza et al. [34] (see Figure 1) and the results obtained were fitted to the circuit using a simplex algorithm, described elsewhere [35]. In Figure 2, an impedance measurement of a 5\% silica fume mortar sample obtained using the contacting method is shown. The causal, linear, and stable nature of the data recorded was validated using the Kramers-Kronig relations, described elsewhere [36]. An example of the experimental Bode plots, as well as the validation of the data obtained during this study using these relations, is presented in Figure 3.
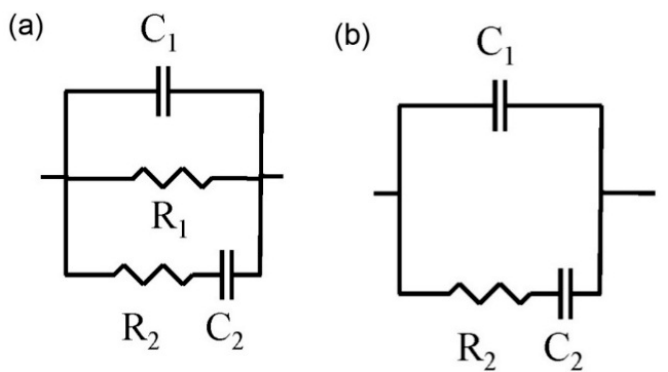

Figure 1. (a) Equivalent circuit used for the fitting of the impedance spectra obtained using the contacting method. (b) Equivalent circuit used for the fitting of the impedance spectra obtained using the non-contacting method.

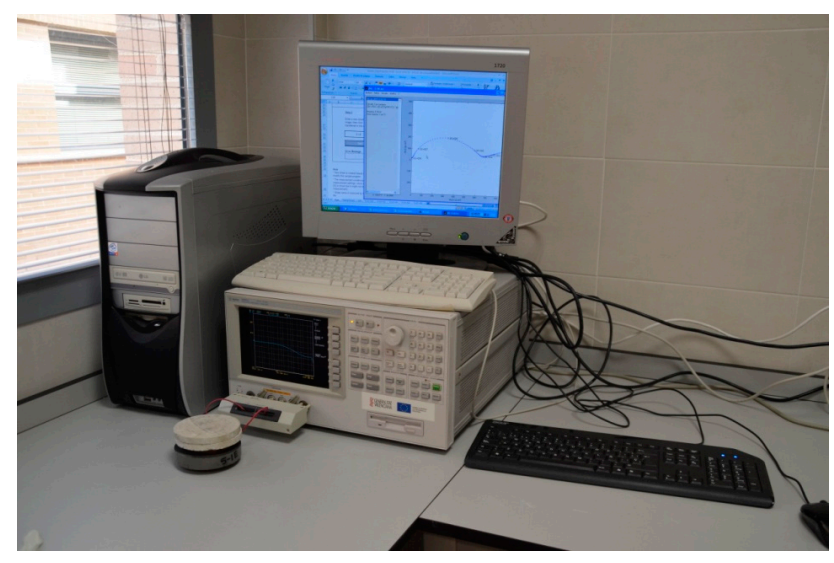

Figure 2. Impedance measurement of a 5\% silica fume mortar sample made using the contacting method. 

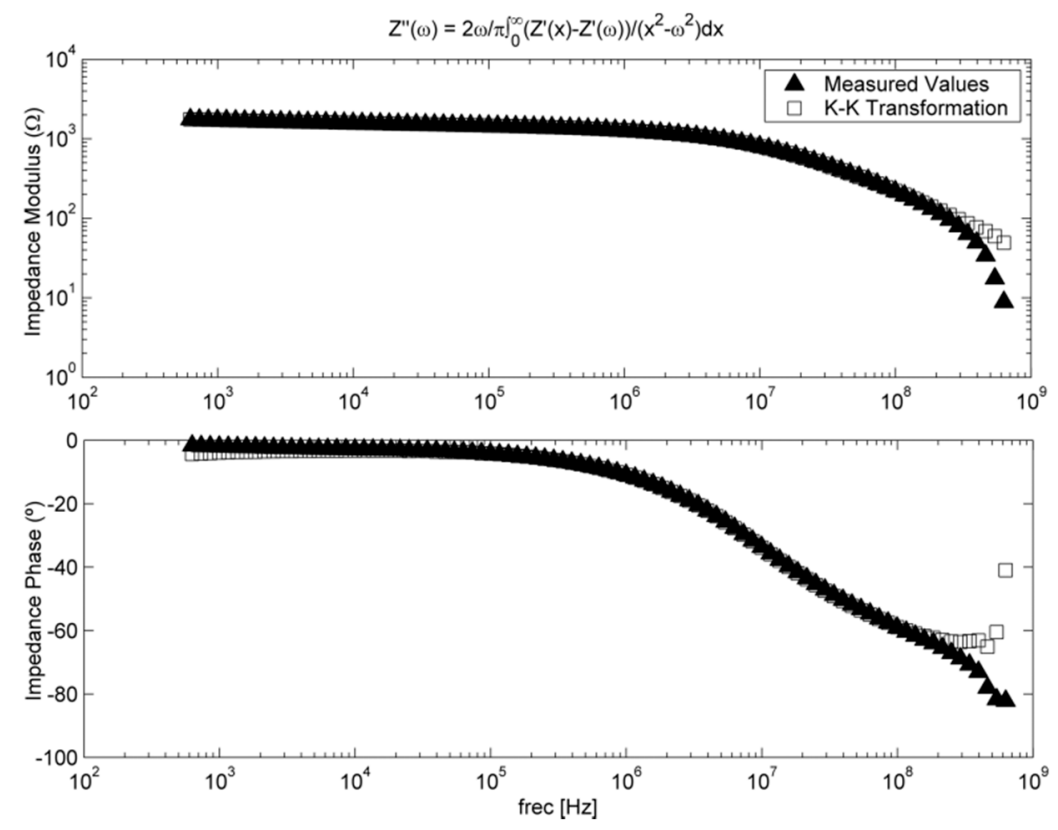

Figure 3. Example of the validation of one of the impedance spectra obtained using the Kramers-Kronig transformations. The impedance spectrum has been represented using the Bode plot, which is divided in two plots, one with the impedance modulus (top) and another with the impedance phase (bottom).

It has been accepted that the parameters obtained from the equivalent circuits correspond to the characteristics related to the microstructure and porous network of cementitious materials [37,38]. The resistance $R_{1}$ corresponds to the total volume of permeable pores crossing the whole sample, and has been observed to be greatly affected by the tortuosity of the pore network [12]. The resistance $R_{2}$ is similar, but represents the total volume of pores (permeable and occluded), and as such is more affected by the total porosity of the sample. The dielectric capacitance $C_{1}$ is related to the total solid volume, and the capacitance $C_{2}$ represents the total pore area in contact with the electrolyte, which is also the total surface area of the pores in the saturated samples. Some authors have argued that by using the contacting method, it is only possible to accurately determine values for the resistance $R_{1}$ due to problems of verifying the goodness of fit [12]. As such, the other parameters analysed were obtained using the non-contacting method. For each mortar type and solution, four different samples were tested. The variation in impedance parameters was monitored until 90 days of immersion in the sulphate solutions.

\subsection{Resistivity}

A Torrent Permeability Tester portable kit, Proceq, Schwerzenbach, Switzerland, conforming to Swiss standard SIA 262/1 [39], with a built in resistivity measurement function, was used to take electrical resistivity measurements. The samples were $7.5 \mathrm{~cm}$ diameter by $30 \mathrm{~cm}$ cylinders, and the measurements were taken using the four electrode "Wenner" method, described elsewhere [40-42], see Figure 4. Calibration of the apparatus was performed using a printed circuit board supplied with the kit with a known resistivity of $12 \mathrm{k} \Omega \mathrm{cm}$. Four measurements were taken for each sample, and the mean value is presented. 


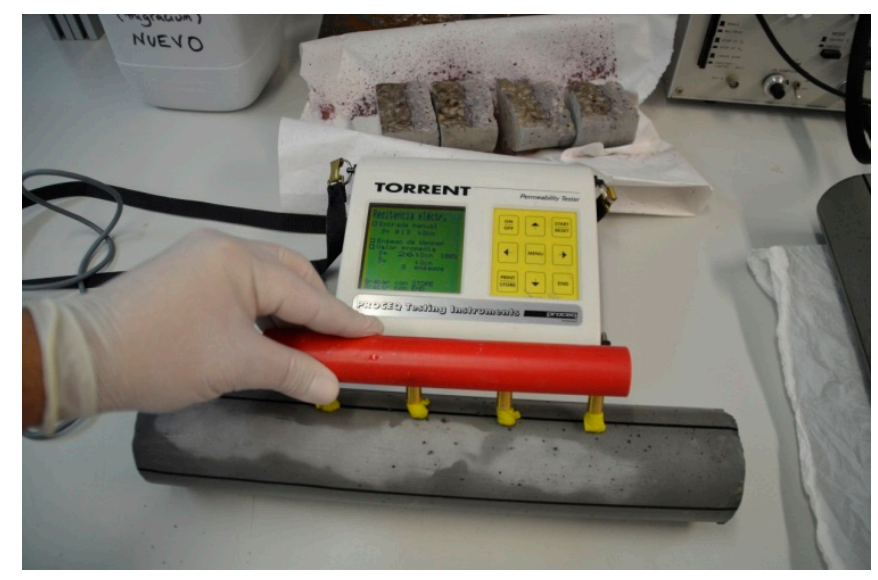

Figure 4. Electrical resistivity measurement of a $10 \%$ silica fume sample made using the four-electrode "Wenner" method.

\subsection{Mercury Intrusion Porosimetry}

An Autopore IV 9500 (Micromeritics Instrument Corp., Norcross, GA, USA) porosimeter was used, permitting the determination of the volume of the pores whose accessible diameter is between $5 \mathrm{~nm}$ and $900 \mu \mathrm{m}$. Samples were obtained from 2-cm height disks, which were oven dried at $50{ }^{\circ} \mathrm{C}$ for at least one week prior to testing. This low temperature was used on the one hand to avoid any microstructural damage due to the high temperatures, and on the other hand to avoid ettringite destruction $[28,43,44]$. Two measurements were taken for each material. Total porosity, pore size distribution, and mercury $(\mathrm{Hg})$ retained at the end of the test were studied. The tests were performed at 21,60 , and 90 days of immersion in the sulphate solutions.

\subsection{Compressive Strength}

The compressive strength was measured according to the Spanish standard UNE EN 196-1 [32]. Three different $4 \times 4 \times 5.3 \mathrm{~cm}$ prismatic specimens were tested for each mortar type and solution. The compressive strength was determined at 21, 60 and 90 days of exposure to the aggressive sulphate solutions.

\section{Results}

\section{1. $0 \%$ Silica Fume Mortars}

The impedance spectroscopy parameter results for $0 \%$ silica fume mortars are depicted in Figure 5. In general, these results were very similar in all of the samples, regardless of the aggressive sulphate solution. A general increase in $R_{1}$ may be observed (Figure $5 \mathrm{a}$ ), while $R_{2}$ remained relatively constant after an initial increase (Figure $5 b$ ) and $C_{1}$ slightly decreased (Figure $5 c$ ). For the samples immersed in the mixed sulphate solution, $R_{2}$ increased and $C_{1}$ decreased after approximately 60 days. In the case of the capacitance $C_{2}$ (Figure $5 \mathrm{~d}$ ), this parameter showed a slight decreasing tendency in all samples. On the other hand, the resistivity results (presented in Figure 6) increased with the exposure period for the majority of the specimens. 


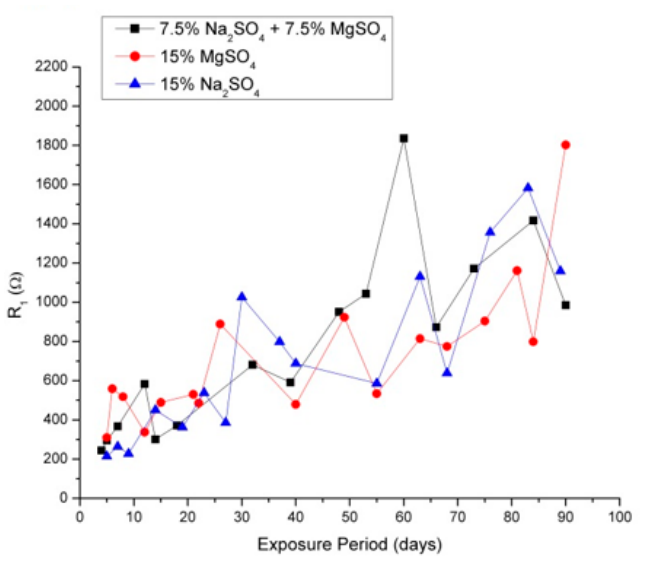

(a)

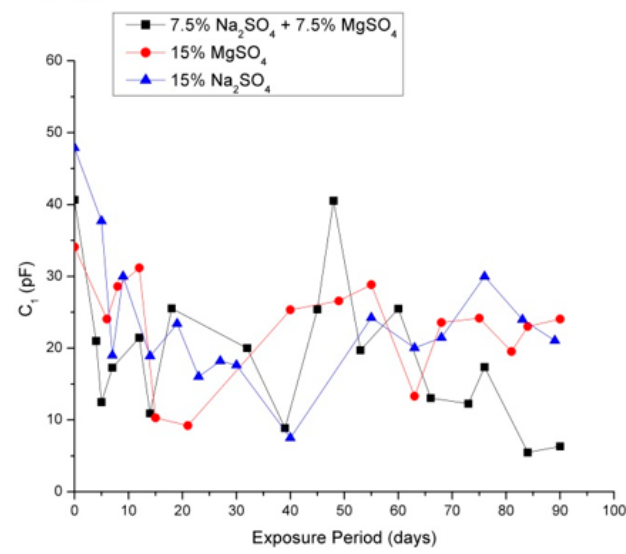

(c)

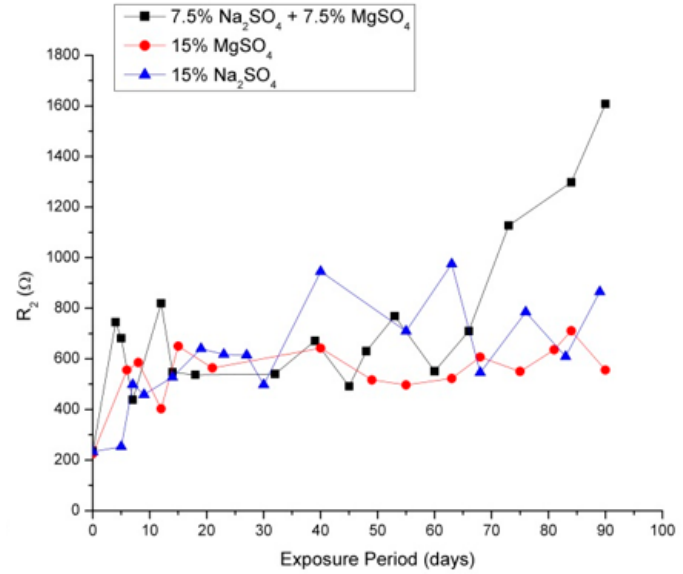

(b)

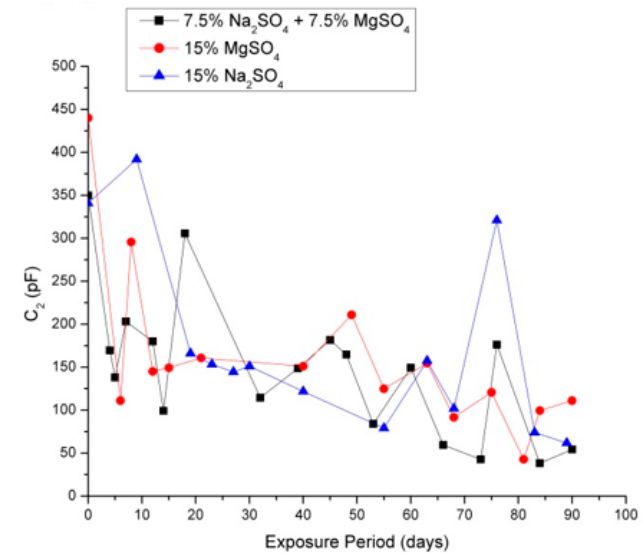

(d)

Figure 5. (a) Variation in impedance spectroscopy resistance $R_{1}$ in mortars with $0 \%$ silica fume; (b) Variation in impedance spectroscopy $R_{2}$ in mortars with $0 \%$ silica fume; (c) Variation in impedance spectroscopy capacitance $C_{1}$ in mortars with $0 \%$ silica fume; (d) Variation in impedance spectroscopy capacitance $C_{2}$ in mortars with $0 \%$ silica fume.

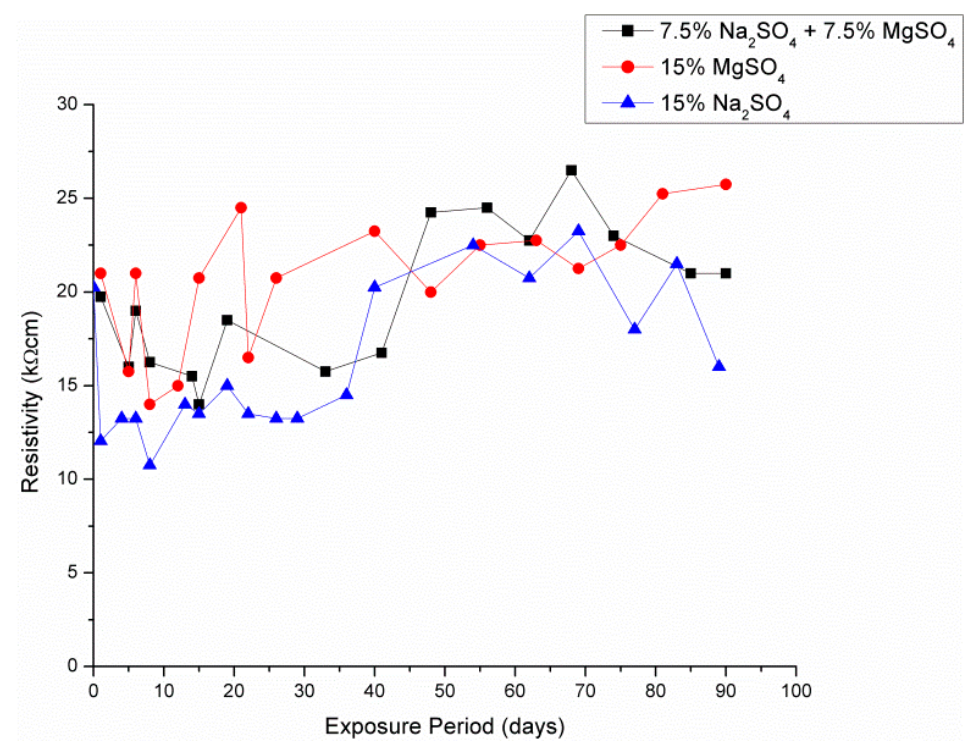

Figure 6. Variation in resistivity in mortars containing $0 \%$ silica fume. 
Regarding the mercury intrusion porosimetry results (see Figure 7), these suggest that the porosity was greater in the samples exposed to the sodium sulphate solution, and increased slightly with exposure time, whereas in the other solutions it remained relatively constant. The $\mathrm{Hg}$ retained at the end of the experiment was very similar for all the $0 \%$ silica fume mortars, and it remained practically constant during the study.

(a)

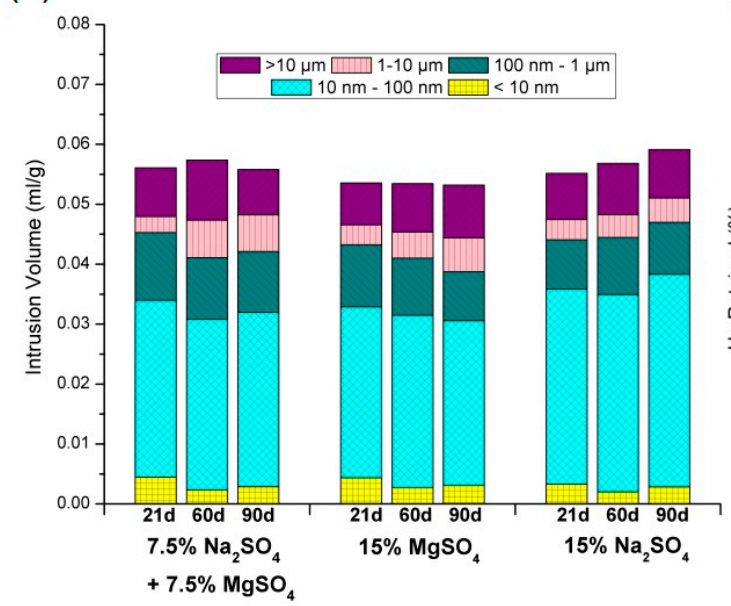

(b)

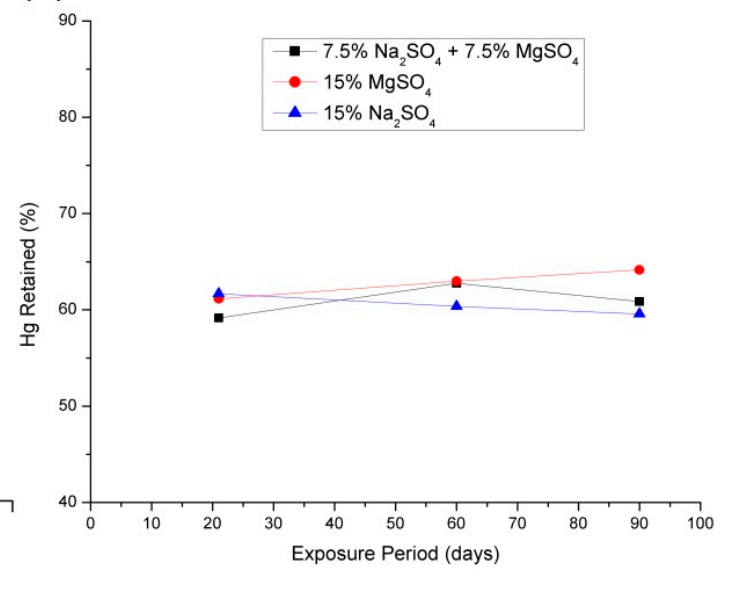

Figure 7. (a) Volume of pores per decade in samples containing $0 \%$ silica fume at 21,60 and 90 days exposure to the three solutions; (b) Percentage of mercury retained in samples containing $0 \%$ silica fume at 21, 60 and 90 days exposure to the three solutions.

The loss in compressive strength was greatest in the samples exposed to the $15 \% \mathrm{Na}_{2} \mathrm{SO}_{4}$ solution, as can be observed in Figure 8, and the samples exposed to the $15 \% \mathrm{MgSO}_{4}$ solution showed the greatest values of this parameter.

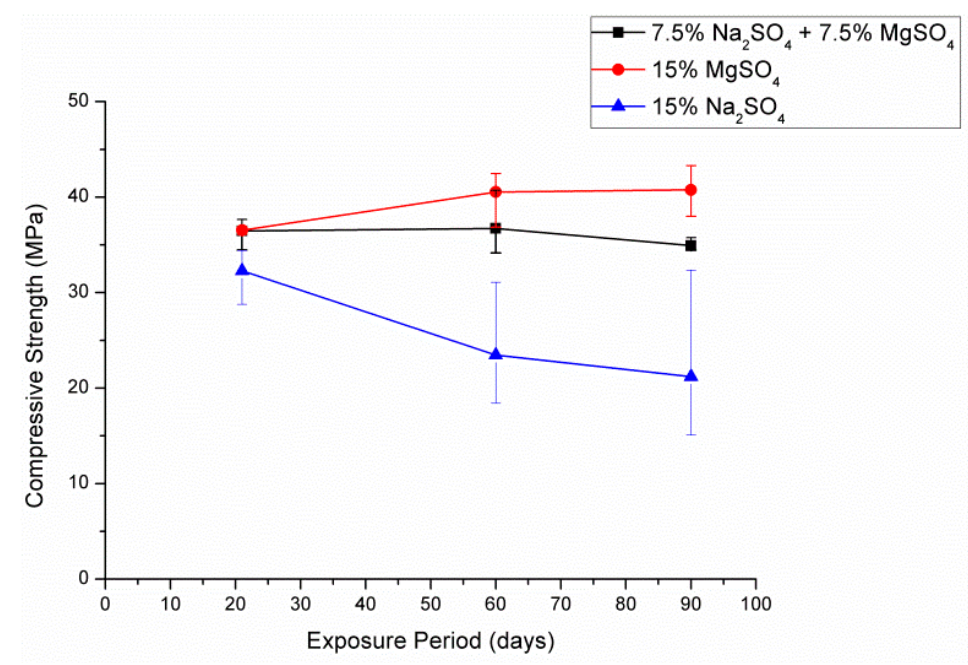

Figure 8. Variation in compressive strength in mortars containing $0 \%$ silica fume exposed to the three different sulphate solutions.

\section{2. $5 \%$ and $10 \%$ Silica Fume Mortars}

The variation in impedance spectroscopy parameters for the mortars containing $5 \%$ silica fume is shown in Figure 9. The resistance $R_{1}$ showed a similar tendency (see Figure 9a) for the different aggressive media; this parameter increased at early ages and decreased later. However, the greatest 
decrease was observed in the samples exposed to the mixed sulphate solution, whereas the samples exposed to the $15 \% \mathrm{MgSO}_{4}$ solution only experienced a slight reduction. This reduction was not observed in the $R_{2}$ and $C_{1}$ parameters in the same samples (see Figure $9 \mathrm{~b}, \mathrm{c}$ ) and in those exposed to the mixed solution, it was much less pronounced than the reduction in the $R_{1}$ resistance. The $C_{2}$ capacitance results (see Figure 9d) fell progressively for all the aggressive solutions studied, although the greatest decrease corresponded to the samples exposed to the mixed sulphate solution. The resistivity results for the $5 \%$ silica fume mortars correlated well with the $R_{1}$ parameter (see Figure 10), although the reduction in the samples exposed to the $15 \% \mathrm{MgSO}_{4}$ solution was somewhat greater.

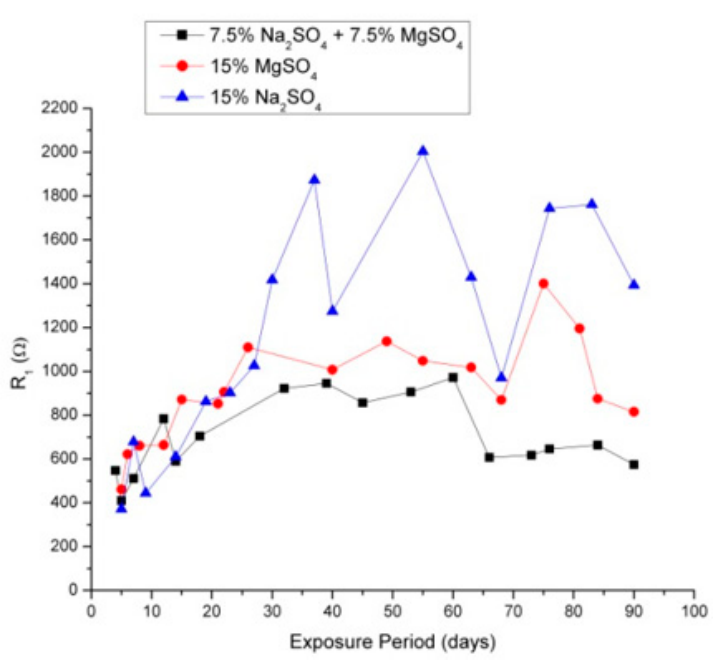

(a)

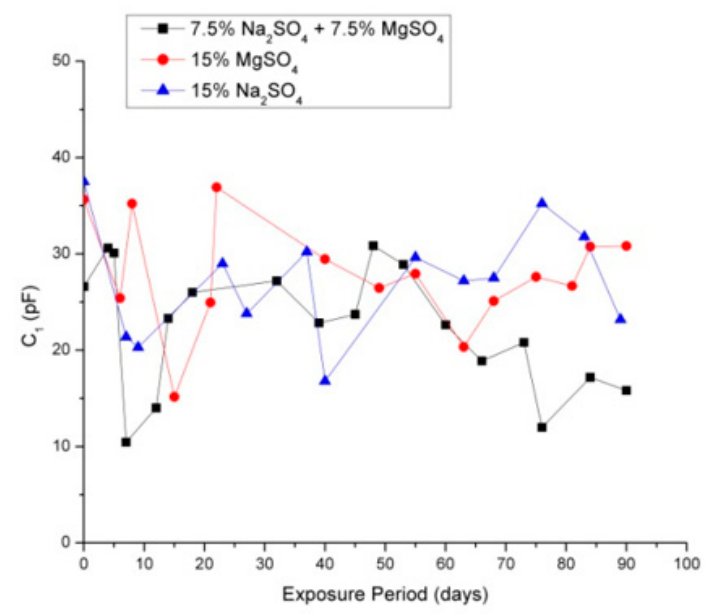

(c)

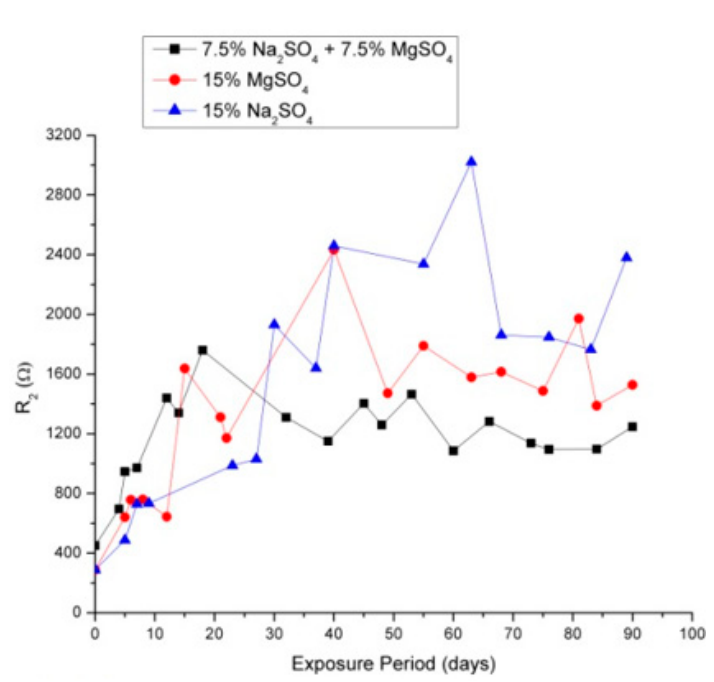

(b)

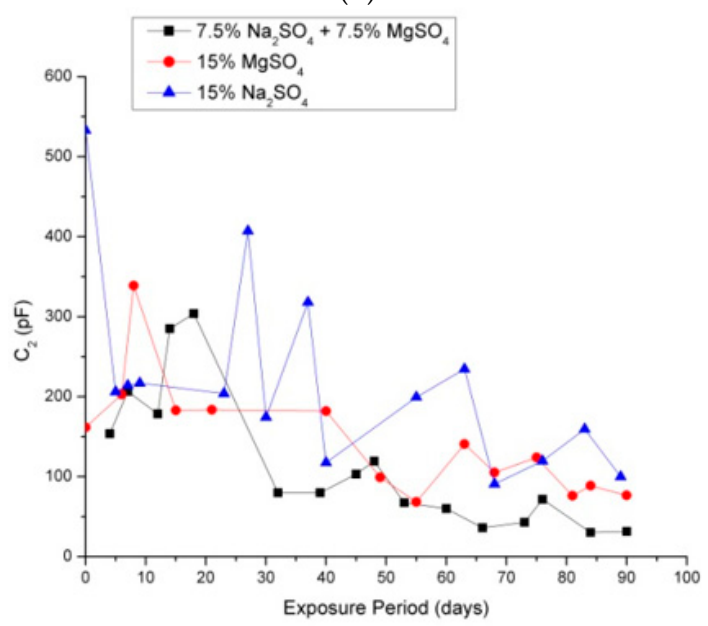

(d)

Figure 9. (a) Variation in impedance spectroscopy resistance $R_{1}$ in mortars with $5 \%$ silica fume; (b) Variation in impedance spectroscopy $R_{2}$ in mortars with $5 \%$ silica fume; (c) Variation in impedance spectroscopy capacitance $C_{1}$ in mortars with $5 \%$ silica fume; (d) Variation in impedance spectroscopy capacitance $C_{2}$ in mortars with $5 \%$ silica fume. 


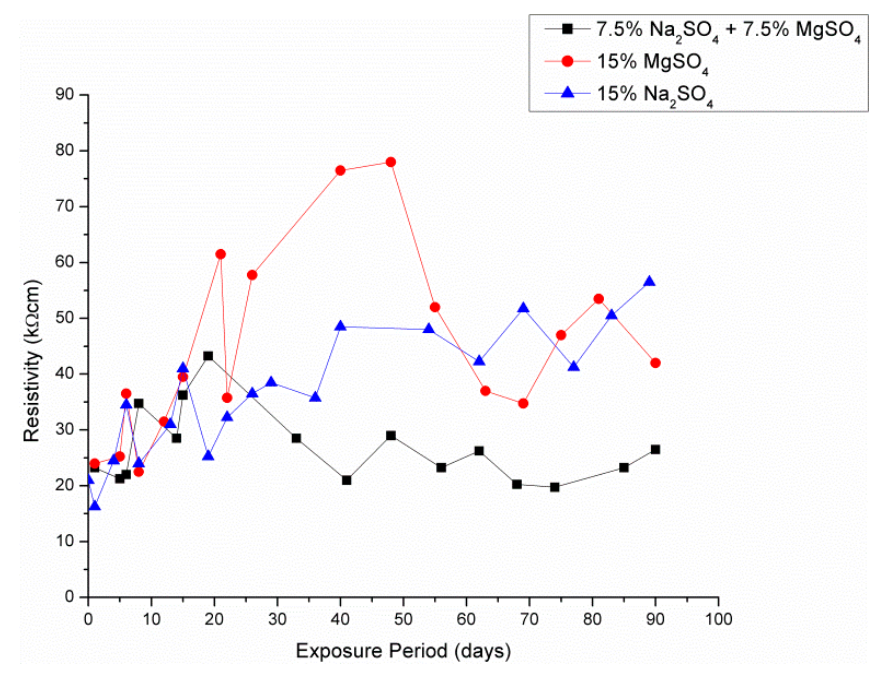

Figure 10. Variation in resistivity in mortars containing 5\% silica fume.

The impedance spectroscopy results for the 10\% silica fume mortars, presented in Figure 11, differed from those measured for the 5\% silica fume ones in several aspects. Firstly, the reduction in the $R_{1}$ parameter (see Figure 11a) was much greater in the samples exposed to the mixed sulphate solution, and by the end of the test period the resistance values were in fact lower than at the beginning. The samples exposed to the $15 \% \mathrm{MgSO}_{4}$ solution also showed a more noticeable decrease in $R_{1}$ resistance with the exposure period. However, the greatest differences were observed in the $R_{2}$ and $C_{1}$ parameters (see Figure 11b,c). In the samples exposed to the mixed sulphate solution, a clear decrease may be observed in these values, which was especially noticeable in the $C_{1}$ capacitance (see Figure 11c). The $10 \%$ silica fume samples exposed to the $15 \% \mathrm{Na}_{2} \mathrm{SO}_{4}$ solution showed a constant increase in both $R_{1}$ and $R_{2}$. The capacitance $C_{2}$ for these samples (see Figure $11 \mathrm{~d}$ ) was also lowest in the samples exposed to the mixed sulphate solution, and remained relatively constant in the samples exposed to the $15 \% \mathrm{Na}_{2} \mathrm{SO}_{4}$ solution. The resistivity results of $10 \%$ silica fume mortars (see Figure 12) also correlate well with the $R_{1}$ resistance values obtained, as noted in the $5 \%$ silica fume mortars.

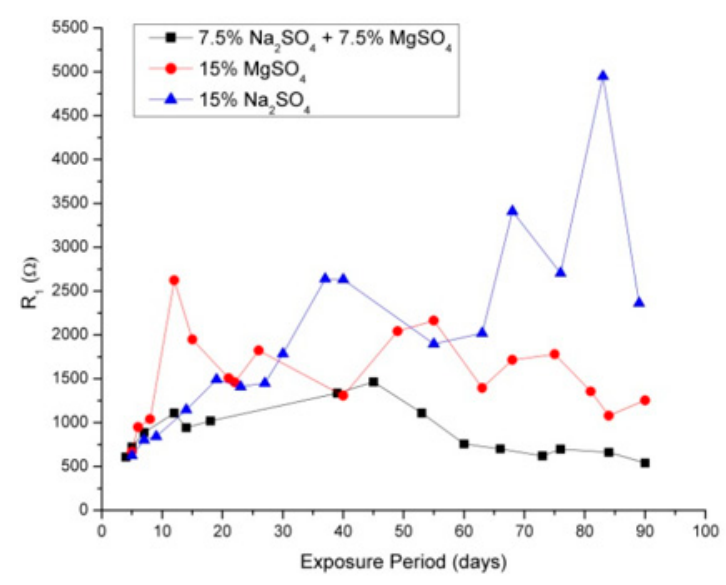

(a)

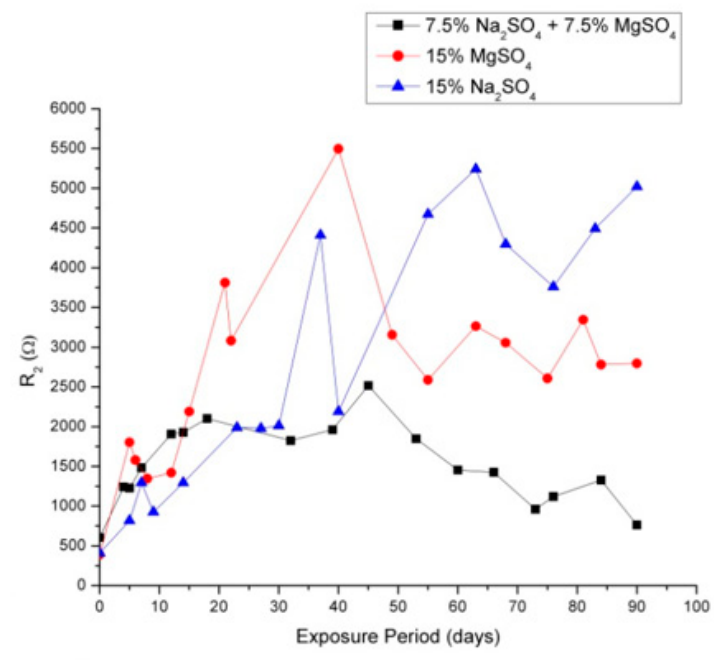

(b)

Figure 11. Cont. 


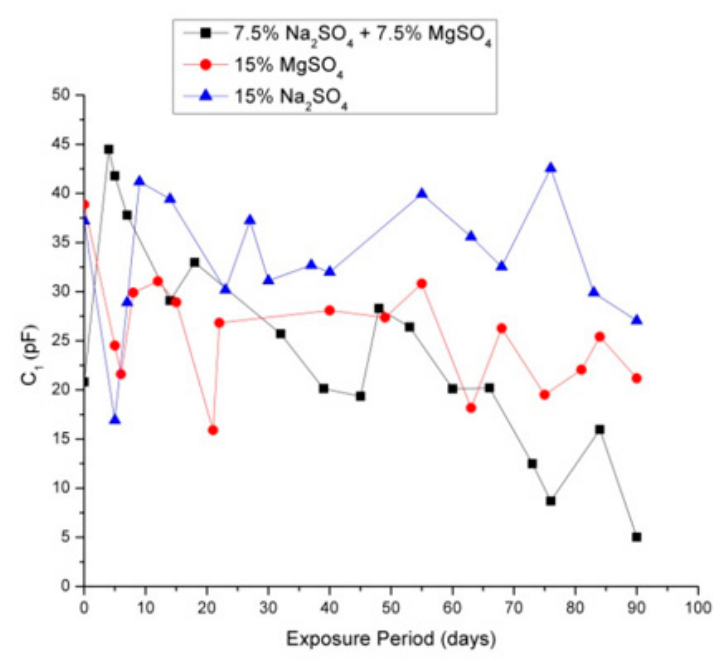

(c)

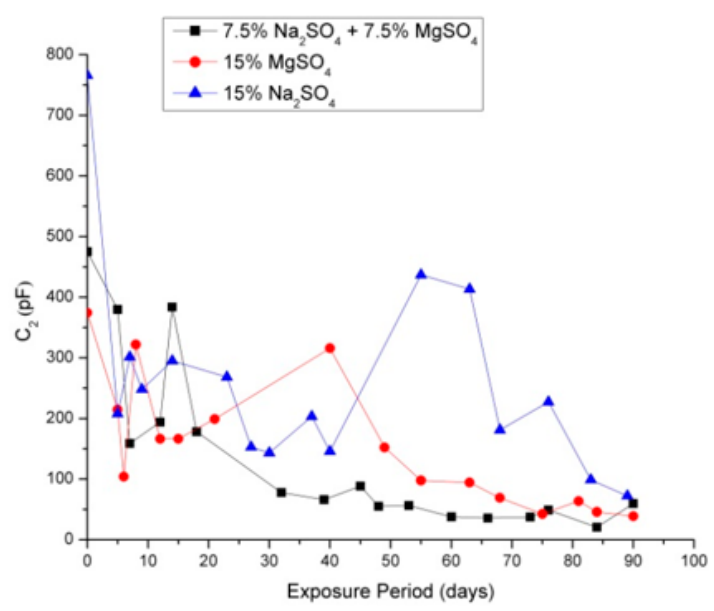

(d)

Figure 11. (a) Variation in impedance spectroscopy resistance $R_{1}$ in mortars with $10 \%$ silica fume; (b) Variation in impedance spectroscopy $R_{2}$ in mortars with $10 \%$ silica fume; (c) Variation in impedance spectroscopy capacitance $C_{1}$ in mortars with $10 \%$ silica fume; (d) Variation in impedance spectroscopy capacitance $C_{2}$ in mortars with $10 \%$ silica fume.

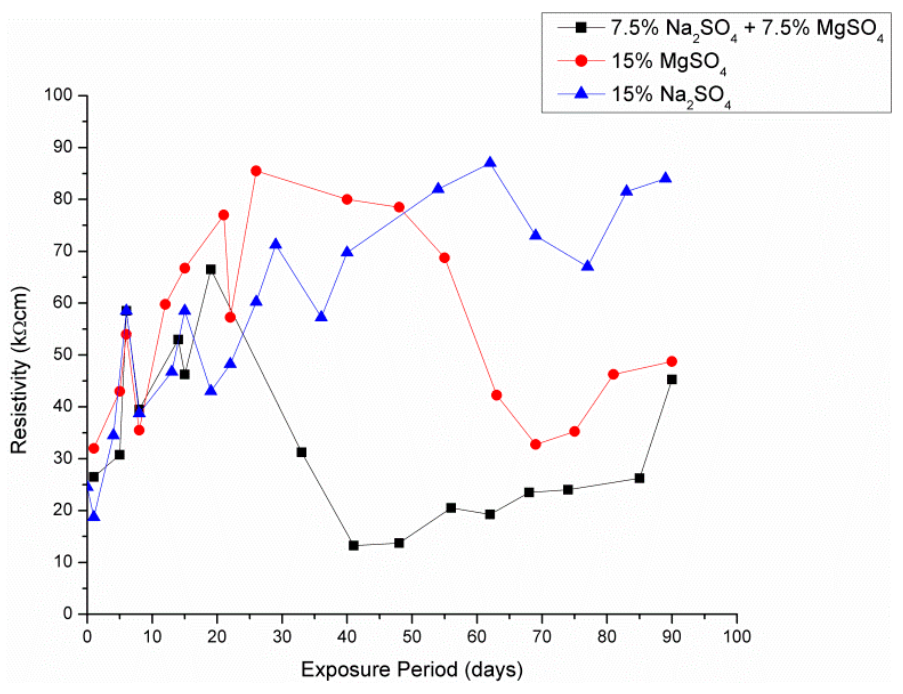

Figure 12. Variation in resistivity in mortars containing $10 \%$ silica fume.

Regarding the mercury intrusion porosimetry results for the 5\% silica fume mortars (see Figure 13), the samples exposed to the mixed solution showed a reduction in intrusion volume, which would suggest a decrease in porosity, and for the other solutions this parameter hardly changed. For the $10 \%$ silica fume mortars (see Figure 14), it was observed that only a slight increase in intruded mercury was recorded in the samples exposed to solutions containing magnesium, and in the samples exposed to the $15 \% \mathrm{Na}_{2} \mathrm{SO}_{4}$ solution, a slight reduction in the total volume of mercury intruded was observed. Additionally, no important changes in retained mercury were recorded for any of the samples containing silica fume (Figures 13 and 14). 
(a)

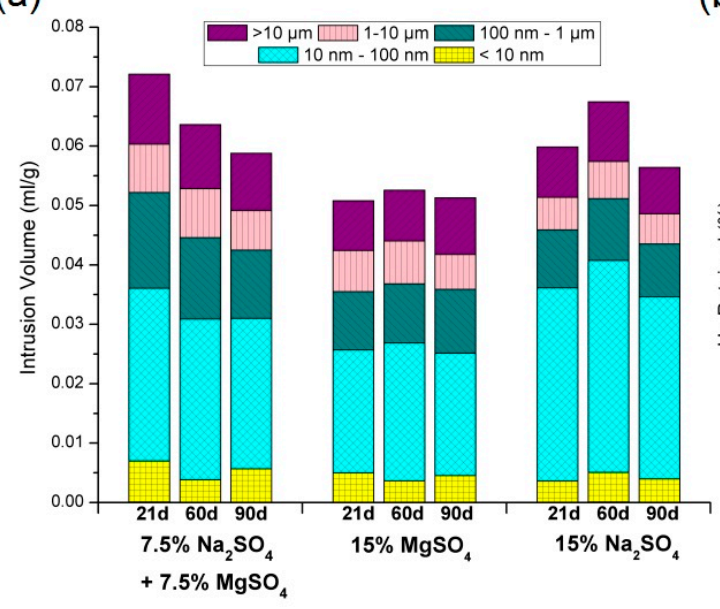

(b)

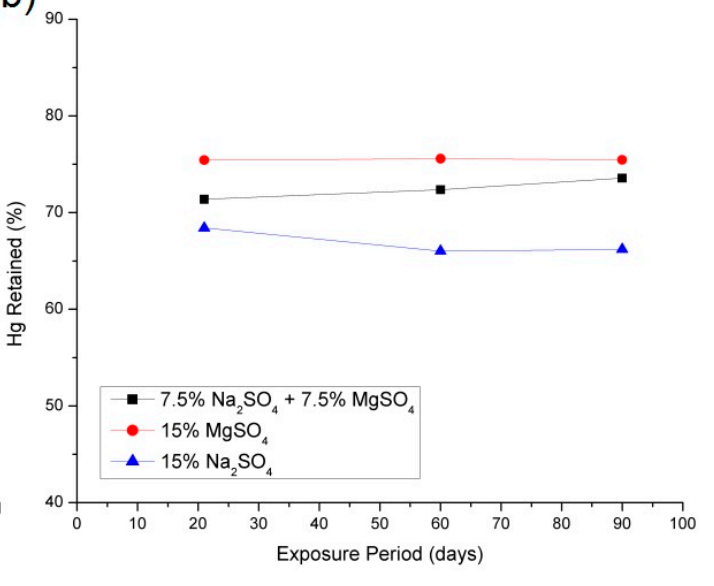

Figure 13. (a) Volume of pores per decade in samples containing 5\% silica fume at 21, 60 and 90 days exposure to the three solutions; (b) Percentage of mercury retained in samples containing $5 \%$ silica fume at 21,60 and 90 days exposure to the three solutions.

(a)

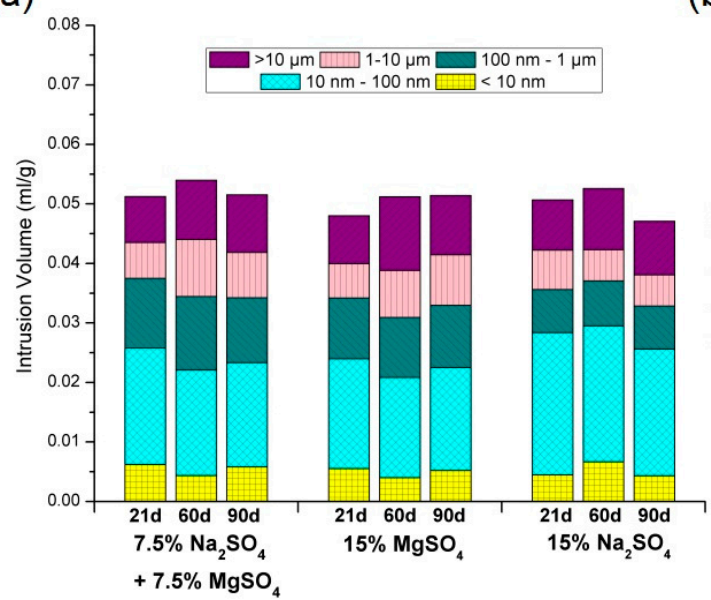

(b)

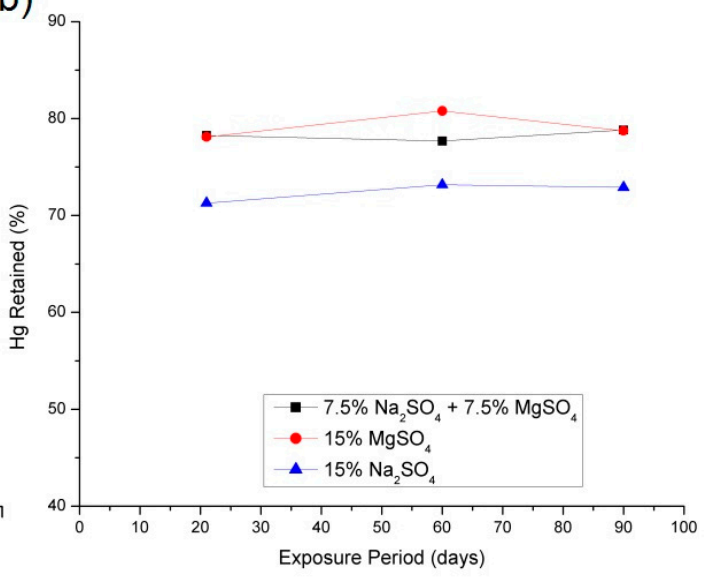

Figure 14. (a) Volume of pores per decade in samples containing 10\% silica fume at 21, 60 and 90 days exposure to the three solutions; (b) Percentage of mercury retained in samples containing $10 \%$ silica fume at 21,60 and 90 days exposure to the three solutions.

Finally, regarding the compressive strength of the silica fume mortars, the results for the $5 \%$ silica fume samples (shown in Figure 15) indicate that despite the total concentration of magnesium ions being greatest in the $15 \% \mathrm{MgSO}_{4}$ solution, the deterioration observed was more severe in the mixed solution at 90 days of exposure, although the initial compressive strength was lowest in the samples exposed to the $15 \% \mathrm{MgSO}_{4}$ solution. From the compressive strength results for the $10 \%$ silica fume samples, presented in Figure 16, the same tendencies noted in the 5\% silica fume samples may be observed. However, in the samples exposed to the mixed sulphate solution, the loss of compressive strength was greater and occurred earlier, and in general the deterioration observed in the samples exposed to the solutions containing magnesium was greater in the samples containing $10 \%$ silica fume. Moreover, the samples exposed to the sodium sulphate solution actually showed an increase in compressive strength, highlighting the minimal effect of sulphate ion exposure. 


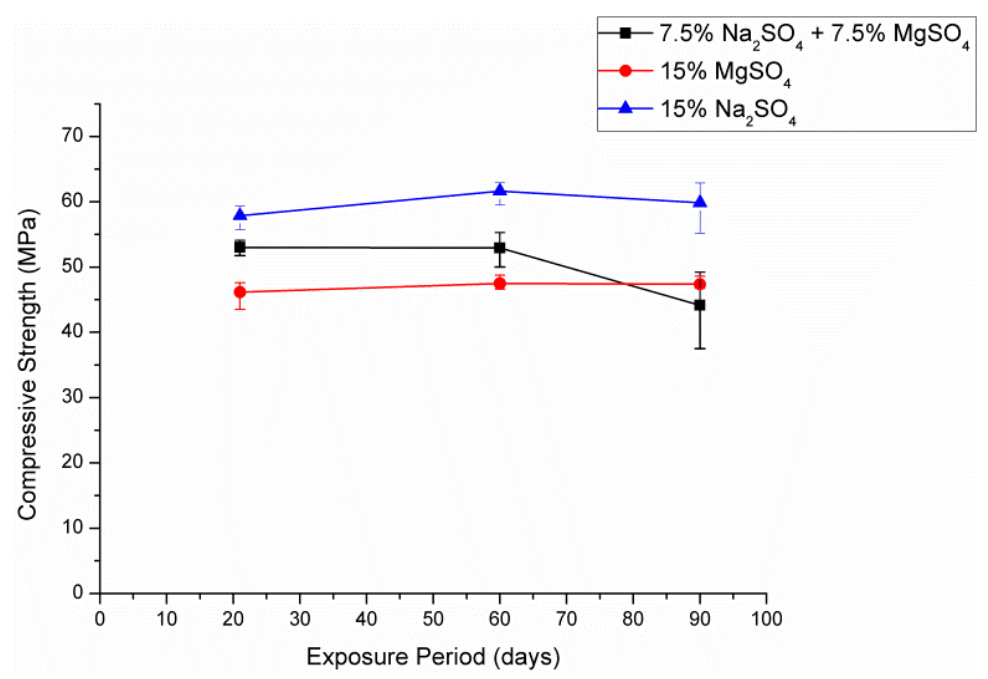

Figure 15. Variation in compressive strength in mortars containing 5\% silica fume.

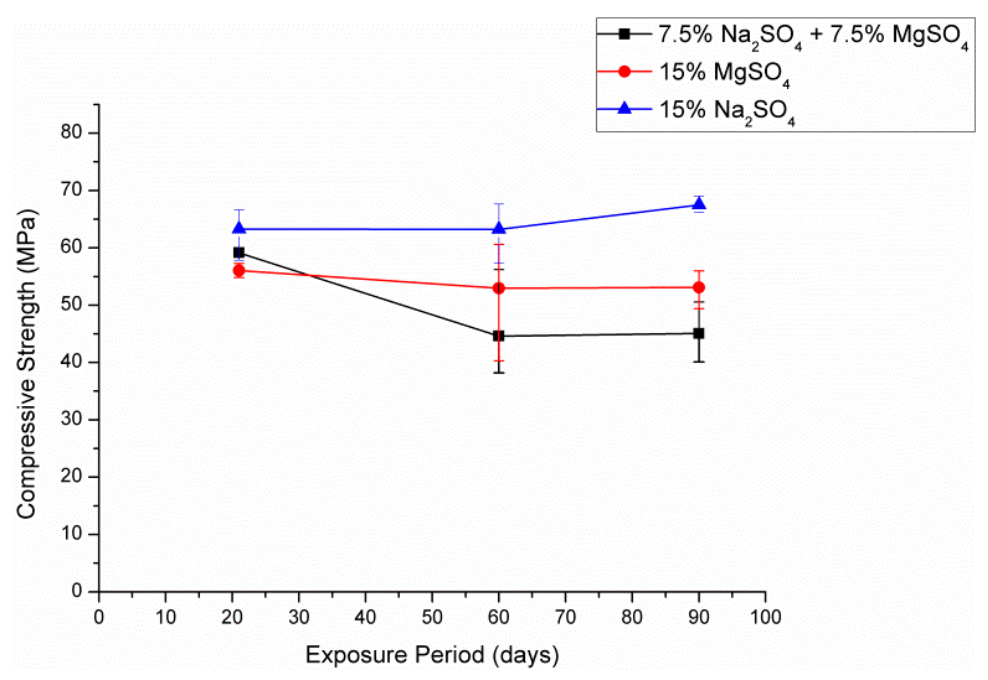

Figure 16. Variation in compressive strength in mortars containing $10 \%$ silica fume.

\section{Discussion}

\subsection{Microstructure Results}

With respect to the non-destructive microstructure characterization of silica fume mortars, firstly the increase in the short-term of the impedance spectroscopy resistances $R_{1}$ and $R_{2}$ in the mortars exposed to the $15 \% \mathrm{Na}_{2} \mathrm{SO}_{4}$ aggressive medium (Figures 9 and 11) could be related to the fact that the pozzolanic reaction of silica fume consumes the portlandite present in the mortars before it can react with the sulphate ions in the solution. Other authors $[10,45]$ have observed that the pozzolanic hydration of cement pastes containing other pozzolanic additives such as fly ash continues well after 28 days. The increase in $R_{1}$ appeared to tail off earlier in the $5 \%$ silica fume mortars, which may be due to the reduced amount of silica fume present. It may also be possible that $\mathrm{Na}_{2} \mathrm{SO}_{4}$ acted as an activator for the pozzolanic reactions [46]. As such, in the samples containing silica fume these reactions would develop faster and their products would increase the tortuosity and the refinement of the mortars' microstructure, that is, an increase of volume of the finer pores of the material and a reduction of the volume of pores with relatively high sizes, as observed by other authors in samples between 28 and 90 days after casting [30]. Furthermore, in mortars without silica fume, the formation 
of expansive products at the initial stages of sulphate attack could also have an influence on the observed increase in impedance spectroscopy resistances. This may be because after initially filling the pores [27], the confinement of expansive reaction products would produce residual stresses, leading to a reduction in compressive strength but not the destruction of the microstructure. As such, it appears that for reasons that probably differ in each of the mortar types, the effect of sulphate ion exposure on the microstructure did not result in a deterioration of the microstructure in any of the samples, as the values of the resistances $R_{1}$ and $R_{2}$ rose.

In the long-term, a reduction of impedance spectroscopy resistances was observed. For $5 \%$ silica fume mortars, this fall was small and the lowest values of these parameters at 90 days corresponded to samples exposed to mixed sulphate solution, which agreed with the electrical resistivity measurements. The capacitance $C_{1}$, which is related to the solid fraction of the sample, did not differ too much for all of the $5 \%$ silica fume mortars, although a slight decrease was also observed at higher ages for those kept in contact with the mixed sulphate solution. These results observed for both resistances and capacitance $C_{1}$ suggests that the principal effect of the decalcification observed was a reduction in the pore network tortuosity as opposed to an increase in the total porosity for the $5 \%$ silica fume mortars. This decrease in tortuosity could be confirmed by the decrease shown by the capacitance $C_{2}$, meaning a smaller contact surface between the electrolyte and solid, possibly resulting from a slight dissolution of hydration products.

For 10\% silica fume samples, the decrease with the exposure period of resistance $R_{1}$ was higher in the samples exposed to the mixed sulphate solution, and it was also considerable for those immersed in the $15 \% \mathrm{MgSO}_{4}$ solution. This suggests that the reduction in the tortuosity of the pore network was more significant in the $10 \%$ silica fume samples. Furthermore, as has been previously described, the reduction in the long-term values of the $R_{2}$ and $C_{1}$ parameters for samples in contact with the aforementioned solutions was much more significant than the fall in resistance $R_{1}$. This could mean an important reduction in the solid volume of these samples, and an increase in porosity. This indicates that the deleterious reactions were especially severe, and is also corroborated by the electrical resistivity results (Figure 12). This also reinforces the idea that the deterioration mechanism is not proportional to the concentration of magnesium present, as the samples exposed to the $15 \% \mathrm{MgSO}_{4}$ solution only experienced a reduction in pore network tortuosity (related to $R_{1}$ ).

Regarding capacitance $C_{2}$, this parameter is associated with the pore surface in contact with the electrolyte present in the material and it is related to the amount of wet pore surface. The $C_{2}$ parameter increased at early ages for silica fume samples exposed to $15 \% \mathrm{Na}_{2} \mathrm{SO}_{4}$. This result is in agreement with the results observed in the resistances $R_{1}$ and $R_{2}$ results already discussed. The rise of capacitance $C_{2}$ could indicate the formation of solids on the pore walls, probably due to continued pozzolanic hydration, and which may be accelerated by the activation effect of $\mathrm{Na}_{2} \mathrm{SO}_{4}$ [46], or the formation of products of the reaction with sulphate ions [27]. Nevertheless, at higher ages the $C_{2}$ capacitances measured in silica fume mortars in contact with the $\mathrm{Na}_{2} \mathrm{SO}_{4}$ solution decreased. This could suggest that the negative effects of exposure to the solution in the mortar's microstructure began to be noticeable, producing a progressive destruction of irregularities on the pore surface.

The silica fume mortars immersed in $15 \% \mathrm{MgSO}_{4}$ and in mixed sulphate solution showed a small increase in capacitance $C_{2}$ at very early ages, although this parameter started to fall quickly. The lowest values were observed for the mixed sulphate solution. This result would suggest that there was a loss of pore surface area, which was greatest in the samples exposed to the mixed sulphate solution. This could mean that the deleterious reactions affected the surface area of the pore network in the samples exposed to solutions containing magnesium, probably due to the dissolution of the most exposed hydrated cement structures within the pore network as a result of decalcification, resulting in a "smoothing" of the pore walls.

The more severe deterioration in the microstructure of silica fume mortars exposed to mixed solution, indicated by impedance spectroscopy parameters, was almost certainly caused by the reaction described in Equation (4), as an X-ray diffraction analysis of the white precipitate which formed on the 
samples (whose presence was also noted by other authors [19]) showed the presence of the magnesium silica hydrate Sepiolite (see Figure 17). It should be noted that although the peaks are relatively small, only crystalline compounds are detected by $\mathrm{X}$-ray diffraction, and many magnesium silica hydrates are amorphous.

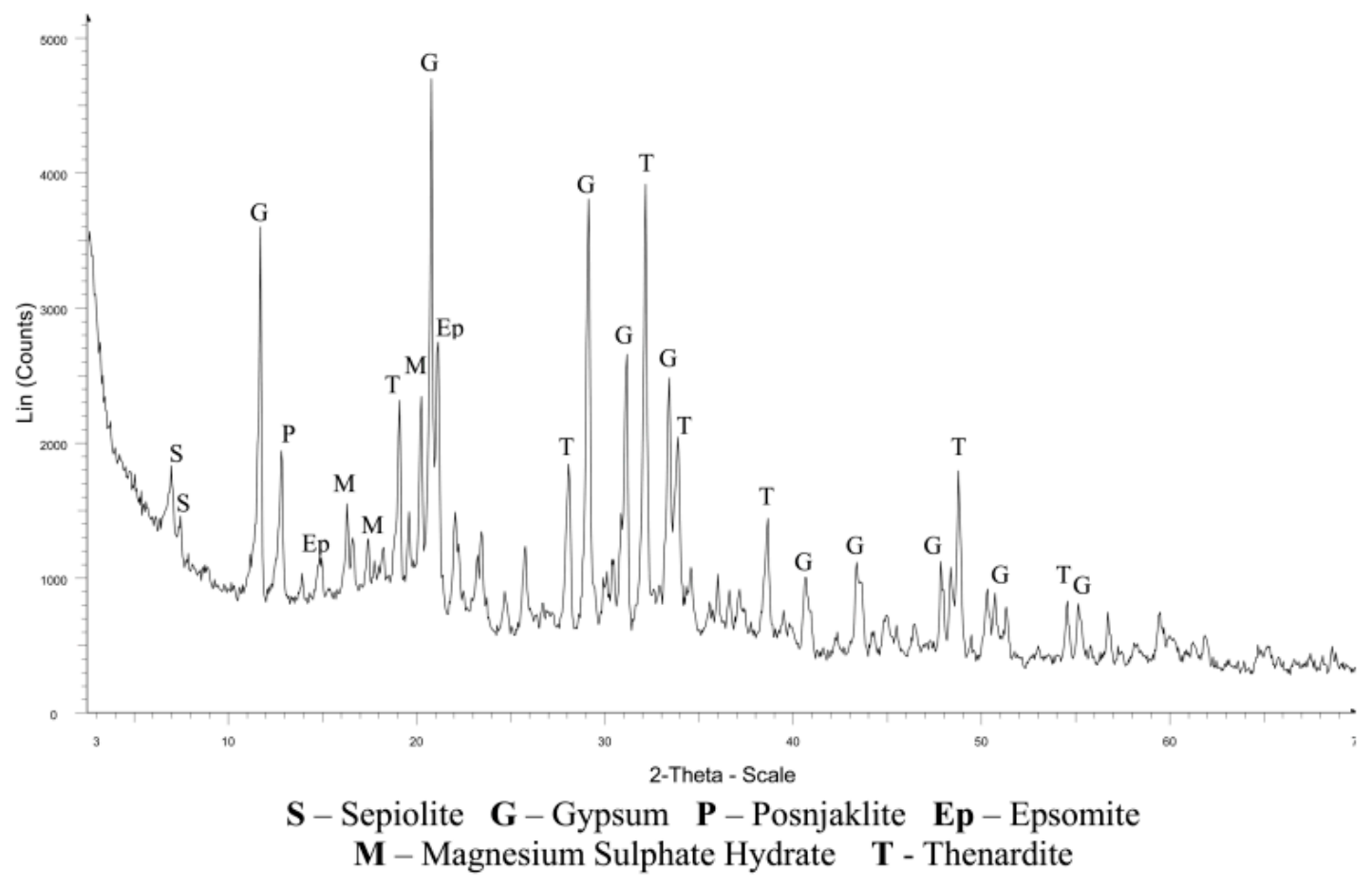

Figure 17. Results of the X-ray diffraction analysis performed on the white precipitate which formed on samples exposed to magnesium sulphate solutions. The formulations of the phases are sepiolite, $\mathrm{Mg}_{4} \mathrm{Si}_{6} \mathrm{O}_{15}(\mathrm{OH})_{2} \cdot 6 \mathrm{H}_{2} \mathrm{O}$; gypsum, $\mathrm{CaSO}_{4} \cdot 2 \mathrm{H}_{2} \mathrm{O}$; posnjaklite, $\mathrm{Cu}_{4} \mathrm{SO}_{4}(\mathrm{OH})_{6} \cdot \mathrm{H}_{2} \mathrm{O}$; epsomite, $\mathrm{MgSO}_{4} \cdot 7 \mathrm{H}_{2} \mathrm{O}$; magnesium sulphate hydrate, $\mathrm{M}-\mathrm{S}-\mathrm{H}$; thenardite, $\mathrm{Na}_{2} \mathrm{SO}_{4}$.

Regarding the mercury intrusion porosimetry results, the higher volume of smaller pores observed for the silica fume mortars exposed to $15 \% \mathrm{Na}_{2} \mathrm{SO}_{4}$ could indicate that continued pozzolanic hydration results in a refinement of the mortars' microstructure. These results are in keeping with those obtained using impedance spectroscopy, and they would corroborate the aforementioned possible influence of $\mathrm{Na}_{2} \mathrm{SO}_{4}$, which could play a role as an activator of pozzolanic reactions of silica fume [46].

However, the rest of the results of this technique did not correlate well with the other microstructure results observed, for example the previously mentioned decrease of intrusion volume in the $5 \%$ silica fume mortars immersed in the mixed solution, and also the fact that the $\mathrm{Hg}$ retained remained practically constant for all silica fume samples during the research (Figures 13 and 14), which would appear to imply that the pore network tortuosity and porosity were unaffected by the aggressive media. These results may possibly be explained by the fact that all pores greater than $900 \mu \mathrm{m}$ were not registered by the apparatus. Visible examination of the photographs presented in Figures 18 and 19 suggests that pores of this size may have been formed. As such, the apparent illogical reduction may have been due to the formation of these larger pores, due to an extremely aggressive attack. Additionally, the technique has some intrinsic limitations, and some authors allege that it overestimates the volume of the smaller pores present [47]. Also, the mechanical strength results suggest a loss of strength, while the pore network does not change significantly or even gets more refined. This result adds value to this paper, because the most used (destructive) technique for the pore network characterization of cement based materials seems not to be useful in this case and there 
is a need to investigate new (non-destructive) techniques to study microstructural changes due to sulphate attack.

(a)

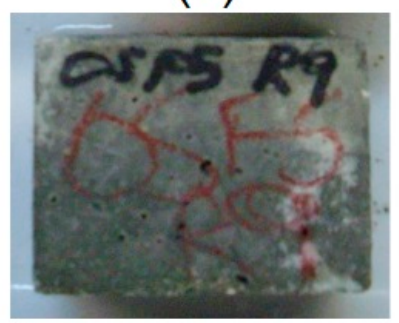

(b)

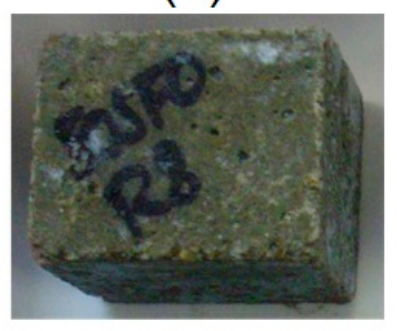

(c)

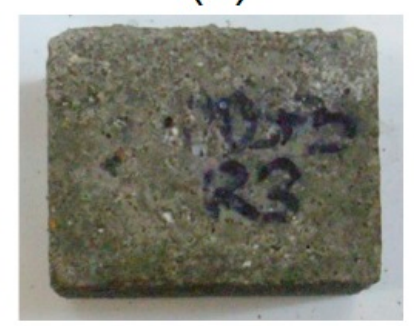

Figure 18. (a) Visual condition of the compressive strength samples containing $5 \%$ silica fume after 90 days exposure to the $15 \%$ sodium sulphate solution; (b) Visual condition of the compressive strength samples containing 5\% silica fume after 90 days exposure to the mixed sulphate solution; (c) Visual condition of the compressive strength samples containing $5 \%$ silica fume after 90 days exposure to the $15 \%$ magnesium sulphate solution.

(a)

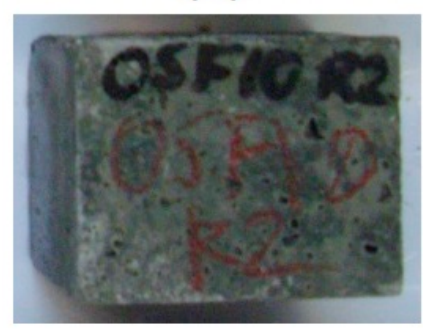

(b)

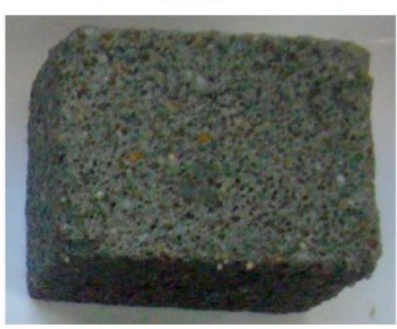

(c)

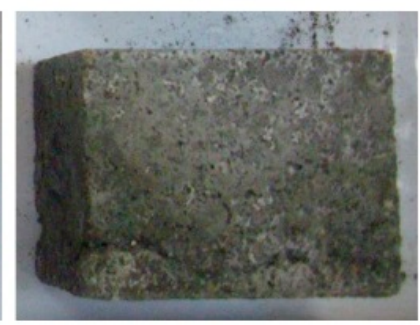

Figure 19. (a) Visual condition of the compressive strength samples containing $10 \%$ silica fume after 90 days exposure to the $15 \%$ sodium sulphate solution; (b) Visual condition of the compressive strength samples containing $10 \%$ silica fume after 90 days exposure to the mixed sulphate solution; (c) Visual condition of the compressive strength samples containing $10 \%$ silica fume after 90 days exposure to the $15 \%$ magnesium sulphate solution.

Regarding the microstructure of the $0 \%$ silica fume mortars, the impedance spectroscopy results were similar for all samples (see Figure 5). The initial relatively high values of the $R_{1}, R_{2}$, and $C_{1}$ parameters could be a consequence of cement hydration. In the long-term, the resistances $R_{1}$ and $R_{2}$ continued increasing, and the capacitance $C_{1}$ remained constant or even decreased. As $C_{1}$ is most closely associated with the total porosity and solid volume of the samples, and resistances have been reported to be more greatly affected by the pore network tortuosity [12], it may be inferred that the formation of expansion products led to an increase in tortuosity in all samples. This was likely due to the formation of reaction products and not cement hydration, as a study on the hydration of paste made using the same cement found that the parameter $R_{1}$ remained constant [48]. Additionally, the lack of an increase in the $C_{1}$ parameter suggests that the total volume of the reaction products is insignificant. A possible interpretation of the progressive fall of the $C_{2}$ capacitance (Figure $5 \mathrm{~d}$ ) in all samples (parameter related to the total pore surface area), could be that the reaction products formed were crystalline in nature, as observed in the Scanning Electron Microscope photographs presented by other authors [19]. As such, their formation may have covered the irregular and rough hydrated cement pore walls with regular forms, leading to an overall reduction in surface area. As discussed previously for the silica fume mortars, only minor changes in the microstructure were observed using mercury intrusion porosimetry, and this result could also be due to the previously mentioned limitations of this technique for registering pores greater than $900 \mu \mathrm{m}$. 
Finally, if the microstructural characterization of silica fume mortars is compared to those without any addition, it may be observed that the values of the impedance spectroscopy $R_{1}$ and $R_{2}$ resistances obtained increased greatly with the silica fume content of the samples (Figures 5, 9 and 11). The electrical resistivity showed a similar tendency, although in general this property was less sensitive for detecting mortars' microstructure changes than impedance spectroscopy, according to the results obtained. In spite of that, the electrical resistivity values for silica fume mortars were also considerably higher than for those without silica fume (Figures 6, 10 and 12). This is in line with the results observed by other authors [49-51] and was once again almost certainly due to the tortuous nature of the pore network formed where silica fume is present. Furthermore, in general it may be noted that the fraction of smaller pores (smaller than $10 \mathrm{~nm}$ ) was greatest in the samples containing $10 \%$ silica fume (Figure 14), which also indicates a more refined microstructure, as suggested by other authors [30,52]. Additionally, the percentage of mercury retained was highest in these samples, and was significantly greater in silica fume mortars compared to the samples without silica fume in all sulphate solutions. This supports the idea that the pore network tortuosity of samples with silica fume blended cement is notably greater than that of ordinary Portland cement samples. However, it appears not to have been as a result of important reductions in porosity, judging from the mercury intrusion porosimetry and impedance spectroscopy results presented in this study, as well as the results observed by other authors $[30,52]$.

\subsection{Compressive Strength Results}

The highest compressive strength results for silica fume mortars corresponded to those exposed to the $15 \% \mathrm{Na}_{2} \mathrm{SO}_{4}$ solution (Figures 15 and 16). This is in agreement with previously discussed microstructure results, and it shows the beneficial effect of silica fume on compressive strength, as well as the possible role of $\mathrm{Na}_{2} \mathrm{SO}_{4}$ as an activator of pozzolanic reactions of silica fume.

The lowest compressive strengths in the long-term for silica fume mortars were observed in magnesium sulphate solutions, especially in the mixed sulphate solution. This result could be expected from the microstructural characterization test results, and could be due to the conversion of conglomerate calcium silica hydrate gels into non-conglomerate magnesium silica hydrates (see Figure 17), which brings a severe loss of compressive strength, according to several authors [21-23]. Nevertheless, in the short-term the compressive strength was smaller for the samples in contact with the $15 \% \mathrm{MgSO}_{4}$ solution than for those exposed to the mixed solution. This result could suggest that the presence of the magnesium ion may have interfered with the hydration process where silica fume blended cements were used.

In spite of that, in general the extent of deterioration in the samples exposed to the $15 \% \mathrm{MgSO}_{4}$ solution was lower than in the results presented by other authors $[18,19,21-23,25,26]$, and it is important to emphasize that the most severe deterioration did not occur in the solution with the greatest concentration of magnesium, as discussed previously. This could mean that the deterioration mechanism in the samples containing silica fume blended cements is complex, and possibly that the deterioration does not depend solely on the concentration of magnesium ions present. Other authors have noted that in solutions with different ionic ratios, the effects are not necessarily in line with those that would be expected considering solely the concentrations of individual aggressive ions present [53].

With respect to $0 \%$ silica fume mortars, the highest compressive strengths were observed for the $15 \% \mathrm{MgSO}_{4}$ solution, despite this solution having the greatest concentration of sulphate ions (see Table 2), whereas the loss in this parameter was greatest in the samples exposed to the $15 \% \mathrm{Na}_{2} \mathrm{SO}_{4}$ solution (Figure 8). Therefore, it appears that the presence of magnesium reduces the deleterious effect of sulphate exposure in terms of compressive strength for mortars without silica fume. In fact, there was a clear positive correlation between the ionic ratio of magnesium to sulphate and compressive strength. This appears to correlate well with the results obtained by other authors using less concentrated solutions [19], and strongly suggests that the formation of Brucite reduced the extent of attack by sulphate ions. The reduction in compressive strength observed in samples exposed to the sodium sulphate solution may have resulted from internal stresses caused by the formation of expansive 
reaction products within the pore network, in agreement with the attack mechanism recently proposed by Santhanam et al. [28]. It may be observed from the photographs presented in Figure 20 that the external parts of the samples had broken away, as suggested by the aforementioned mechanism.

(a)

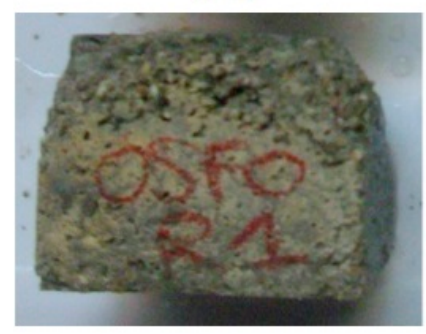

(b)

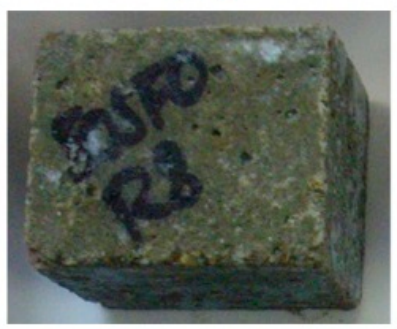

(c)

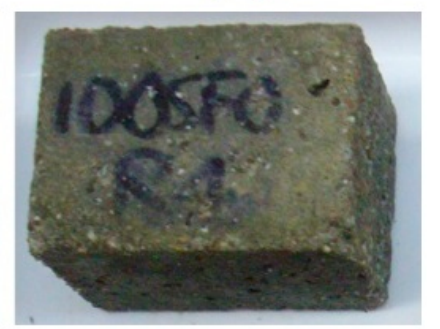

Figure 20. (a) Visual condition of the compressive strength samples containing $0 \%$ silica fume after 90 days exposure to the $15 \%$ sodium sulphate solution; (b) Visual condition of the compressive strength samples containing $0 \%$ silica fume after 90 days exposure to the mixed sulphate solution; (c) Visual condition of the compressive strength samples containing $0 \%$ silica fume after 90 days exposure to the $15 \%$ magnesium sulphate solution.

Lastly, regarding the comparison between the mortars with and without silica fume, it is important to highlight that the compressive strength of the silica fume mortars was much more affected by exposure to the magnesium sulphate solutions, while the greatest deleterious effect on the strength for mortars without silica fume addition was due to exposure to the $15 \% \mathrm{Na}_{2} \mathrm{SO}_{4}$ solution. However, for all aggressive media, the compressive strengths of silica fume mortars were higher than those observed for mortars without silica fume during the exposure period studied.

\section{Conclusions}

The main conclusions that can be drawn from the results previously discussed can be summarized as follows:

- The silica fume mortars immersed in the $15 \% \mathrm{Na}_{2} \mathrm{SO}_{4}$ solution performed well, and showed the most refined microstructure and highest compressive strengths compared to the samples exposed to the other aggressive media studied. This could be related to the beneficial effect of pozzolanic hydration of the silica fume additive, and also thepossible effect of $15 \% \mathrm{Na}_{2} \mathrm{SO}_{4}$ as an activator of pozzolanic reactions in silica fume.

- In all samples containing silica fume, the deterioration observed was greatest in samples exposed to the magnesium sulphate solutions, especially for those exposed to the mixed one, despite the concentration of magnesium ions being lower. This could be due to the formation of non-conglomerate magnesium silica hydrates (as shown by the XRD analysis). However, the mixed solution results appear to suggest that the deterioration mechanism taking place in samples with silica fume blended cement exposed simultaneously to magnesium and sulphate ions is complex, and does not solely depend on reactions involving the magnesium ion.

- In samples without silica fume, the microstructural effects resulting from exposure to each of the aggressive media did not vary greatly. However, regarding the compressive strength, the presence of magnesium appears to have a positive effect on this property, whereas the exposure to the $15 \%$ $\mathrm{Na}_{2} \mathrm{SO}_{4}$ produced a high loss of strength in these samples. The beneficial effect of magnesium could probably be a result of the formation of a Brucite layer, and the negative effect of sodium sulphate on the compressive strength would be a consequence of internal stresses caused by the formation of reaction products. 
- Mercury intrusion porosimetry appears to have limitations when used to monitor changes in cement based samples resulting from magnesium and sodium sulphate attack, possibly due to the influence of pores larger than the maximum diameter measured by the apparatus.

- The results of this study indicate that the addition of silica fume brings a more refined microstructure and a higher compressive strength to mortars exposed to aggressive sodium and magnesium sulphate solutions, compared to mortars with no additions, during the study period.

- According to the microstructural characterization results of this study, it appears that non-destructive impedance spectroscopy is the most sensitive technique for detecting the changes in the porous network of mortars with and without silica fume exposed to aggressive sodium and magnesium sulphate solutions.

Acknowledgments: The research work included in the paper has been financially supported by the "Ministerio de Economía y Competitividad" (formerly "Ministerio de Ciencia e Innovación") of Spain and FEDER through projects BIA2010-20548 and BIA2011-25721, and by the University of Alicante through project GRE13-25. The authors also wish to thank Cementos Portland Valderrivas S.A. and Grupo Ferroatlántica S.A. for providing the cement and silica fume (respectively) used in this study.

Author Contributions: The results included in this paper were obtained in the Master's final project carried out by Mark Williams, under the supervision of José Marcos Ortega, Isidro Sánchez, and Miguel Ángel Climent, to obtain the Materials, Water, and Soil Engineering Master's degree at the University of Alicante (Spain). Mark Williams and José Marcos Ortega wrote the paper and performed the experiments. Isidro Sánchez, Marta Cabeza and Miguel Ángel Climent supervised the research work and revised the paper. All the authors contributed to conceive and design the experiments, and to analyse and discuss the results.

Conflicts of Interest: The authors declare no conflict of interest.

\section{References}

1. Popovics, J.S.; Subramaniam, K.V.L. Review of Ultrasonic Wave Reflection Applied to Early-Age Concrete and Cementitious Materials. J. Nondestruct. Eval. 2014, 34, 267. [CrossRef]

2. Kogbara, R.B.; Iyengar, S.R.; Grasley, Z.C.; Masad, E.A.; Zollinger, D.G. Non-destructive evaluation of concrete mixtures for direct LNG containment. Mater. Des. 2015, 82, 260-272. [CrossRef]

3. Henry, M.; Darma, I.S.; Sugiyama, T. Analysis of the effect of heating and re-curing on the microstructure of high-strength concrete using X-ray CT. Constr. Build. Mater. 2014, 67, 37-46. [CrossRef]

4. Chen, W.; Li, Y.; Shen, P.; Shui, Z. Microstructural Development of Hydrating Portland Cement Paste at Early Ages Investigated with Non-destructive Methods and Numerical Simulation. J. Nondestruct. Eval. 2013, 32, 228-237. [CrossRef]

5. Chaix, J.-F.; Garnier, V.; Corneloup, G. Concrete damage evolution analysis by backscattered ultrasonic waves. NDT E Int. 2003, 36, 461-469. [CrossRef]

6. Demčenko, A.; Visser, H.A.; Akkerman, R. Ultrasonic measurements of undamaged concrete layer thickness in a deteriorated concrete structure. NDT E Int. 2016, 77, 63-72. [CrossRef]

7. Sadowski, Ł.; Stefaniuk, D. Microstructural Evolution within the Interphase between Hardening Overlay and Existing Concrete Substrates. Appl. Sci. 2017, 7, 123. [CrossRef]

8. Díaz, B.; Nóvoa, X.R.; Pérez, M.C. Study of the chloride diffusion in mortar: A new method of determining diffusion coefficients based on impedance measurements. Cem. Concr. Compos. 2006, 28, 237-245. [CrossRef]

9. Ortega, J.M.; Sánchez, I.; Climent, M.A. Impedance spectroscopy study of the effect of environmental conditions in the microstructure development of OPC and slag cement mortars. Arch. Civ. Mech. Eng. 2015, 15, 569-583. [CrossRef]

10. Pastor, J.L.; Ortega, J.M.; Flor, M.; López, M.P.; Sánchez, I.; Climent, M.A. Microstructure and durability of fly ash cement grouts for micropiles. Constr. Build. Mater. 2016, 117, 47-57. [CrossRef]

11. Sánchez, I.; López, M.P.; Ortega, J.M.; Climent, M.Á. Impedance spectroscopy: An efficient tool to determine the non-steady-state chloride diffusion coefficient in building materials. Mater. Corros. 2011, 62, $139-145$. [CrossRef]

12. Sánchez, I.; Antón, C.; de Vera, G.; Ortega, J.M.; Climent, M.A. Moisture Distribution in Partially Saturated Concrete Studied by Impedance Spectroscopy. J. Nondestruct. Eval. 2013, 32, 362-371. [CrossRef] 
13. Ortega, J.M.; Esteban, M.D.; Rodríguez, R.R.; Pastor, J.L.; Sánchez, I. Microstructural Effects of Sulphate Attack in Sustainable Grouts for Micropiles. Materials 2016, 9. [CrossRef]

14. Santhanam, M.; Cohen, M.D.; Olek, J. Mechanism of sulfate attack: A fresh look. Part 1: Summary of experimental results. Cem. Concr. Res. 2002, 32, 915-921. [CrossRef]

15. Palankar, N.; Ravi Shankar, A.U.; Mithun, B.M. Durability studies on eco-friendly concrete mixes incorporating steel slag as coarse aggregates. J. Clean. Prod. 2016, 129, 437-448. [CrossRef]

16. Cohen, M.D.; Mather, B. Sulfate attack on concrete. Research needs. ACI Mater. J. 1991, 88, 62-69.

17. Al-Dulaijan, S.U.; Maslehuddin, M.; Al-Zahrani, M.M.; Sharif, A.M.; Shameem, M.; Ibrahim, M. Sulfate resistance of plain and blended cements exposed to varying concentrations of sodium sulfate. Cem. Concr. Compos. 2003, 25, 429-437. [CrossRef]

18. Cohen, M.D.; Bentur, A. Durability of Portland cement-Silica fume pastes in magnesium sulfate and sodium sulfate solutions. ACI Mater. J. 1988, 85, 148-157.

19. Lee, S.T.; Moon, H.Y.; Swamy, R.N. Sulfate attack and role of silica fume in resisting strength loss. Cem. Concr. Compos. 2005, 27, 65-76. [CrossRef]

20. Neville, A. The confused world of sulfate attack on concrete. Cem. Concr. Res. 2004, 34, 1275-1296. [CrossRef]

21. Al-Amoudi, O.S.B. Performance of 15 reinforced concrete mixtures in magnesium-sodium sulphate environments. Constr. Build. Mater. 1995, 9, 149-158. [CrossRef]

22. Baghabra Al-Amoudi, O.S. Attack on plain and blended cements exposed to aggressive sulfate environments. Cem. Concr. Compos. 2002, 24, 305-316. [CrossRef]

23. Ganjian, E.; Pouya, H.S. Effect of magnesium and sulfate ions on durability of silica fume blended mixes exposed to the seawater tidal zone. Cem. Concr. Res. 2005, 35, 1332-1343. [CrossRef]

24. Ganjian, E.; Pouya, H.S. The effect of Persian Gulf tidal zone exposure on durability of mixes containing silica fume and blast furnace slag. Constr. Build. Mater. 2009, 23, 644-652. [CrossRef]

25. Türker, F.; Aköz, F.; Koral, S.; Yüzer, N. Effects of magnesium sulfate concentration on the sulfate resistance of mortars with and without silica fume. Cem. Concr. Res. 1997, 27, 205-214. [CrossRef]

26. Behfarnia, K.; Farshadfar, O. The effects of pozzolanic binders and polypropylene fibers on durability of SCC to magnesium sulfate attack. Constr. Build. Mater. 2013, 38, 64-71. [CrossRef]

27. Bonen, D.; Cohen, M.D. Magnesium sulfate attack on portland cement paste-I. Microstructural analysis. Cem. Concr. Res. 1992, 22, 169-180. [CrossRef]

28. Santhanam, M.; Cohen, M.D.; Olek, J. Mechanism of sulfate attack: A fresh look. Part 2: Proposed mechanisms. Cem. Concr. Res. 2003, 33, 341-346. [CrossRef]

29. Sánchez, I.; Nóvoa, X.R.; de Vera, G.; Climent, M.A. Microstructural modifications in Portland cement concrete due to forced ionic migration tests. Study by impedance spectroscopy. Cem. Concr. Res. 2008, 38, 1015-1025. [CrossRef]

30. Poon, C.S.; Kou, S.C.; Lam, L. Compressive strength, chloride diffusivity and pore structure of high performance metakaolin and silica fume concrete. Constr. Build. Mater. 2006, 20, 858-865. [CrossRef]

31. Composición, Especificaciones y Criterios de Conformidad de los Cementos Comunes; UNE-EN 197-1:2011; AENOR: Madrid, Spain, 2000; p. 30.

32. Métodos de Ensayo de Cementos. Parte 1: Determinación de Resistencias Mecánicas; UNE-EN 196-1:2005; AENOR: Madrid, Spain, 2005.

33. Standard Test Method for Length Change of Hydraulic-Cement Mortars Exposed to a Sulfate Solution; ASTM C 1012-04; ASTM International: Wesk Conshohocken, PA, USA, 2004; p. 6.

34. Cabeza, M.; Merino, P.; Miranda, A.; Nóvoa, X.R.; Sanchez, I. Impedance spectroscopy study of hardened Portland cement paste. Cem. Concr. Res. 2002, 32, 881-891. [CrossRef]

35. Keddam, M.; Takenouti, H.; Nóvoa, X.R.; Andrade, C.; Alonso, C. Impedance measurements on cement paste. Cem. Concr. Res. 1997, 27, 1191-1201. [CrossRef]

36. Barsoukov, E.; Macdonald, J.R. Impedance Spectroscopy; Barsoukov, E., Macdonald, J.R., Eds.; John Wiley \& Sons: Hoboken, NJ, USA, 2005.

37. Cabeza, M.; Merino, P.; Nóvoa, X.R.; Sánchez, I. Electrical effects generated by mechanical loading of hardened Portland cement paste. Cem. Concr. Compos. 2003, 25, 351-356. [CrossRef]

38. Cabeza, M.; Keddam, M.; Nóvoa, X.R.; Sánchez, I.; Takenouti, H. Impedance spectroscopy to characterize the pore structure during the hardening process of Portland cement paste. Electrochim. Acta 2006, 51, 1831-1841. [CrossRef] 
39. SIA 262/1-e Standars Method. Non-Destructuve Site Air Permeability Test. Swiss-Standard, 2003.

40. Torrent, R.; Fernandez Luco, L. RILEM report 40 non-destructive evaluation of the penetrability and thickness of the concrete cover. In RILEM Report 40: Non-Destructive Evaluation of the Penetrability and Thickness of the Concrete Cover; RILEM: Bagneux, France, 2007.

41. Standard Test Method for Measuring the Surface Resistivity of Hardened Concrete Cylinders or Cores Using the Wenner Four-Electrode Method (Draft); WK37880, A.S.T.M.; International: West Conshohocken, PA, USA, 2012.

42. Durabilidad del Hormigón. Métodos de Ensayo. Determinación de la Resistividad Eléctrica. Parte 2: Método de las Cuatro Puntas o de Wenner; UNE 83988-2:2014; AENOR: Madrid, Spain, 2014.

43. Leklou, N.; Aubert, J.-E.; Escadeillas, G. Influence of various parameters on heat-induced internal sulphate attack. Eur. J. Environ. Civ. Eng. 2013, 17, 141-153. [CrossRef]

44. Kaufmann, J.; Winnefeld, F.; Lothenbach, B. Stability of ettringite in CSA cement at elevated temperatures. Adv. Cem. Res. 2016, 28, 251-261. [CrossRef]

45. Wang, A.; Zhang, C.; Sun, W. Fly ash effects. Cem. Concr. Res. 2004, 34, 2057-2060. [CrossRef]

46. Mostafa, N.Y.; Zaki, Z.I.; Abd Elkader, O.H. Chemical activation of calcium aluminate cement composites cured at elevated temperature. Cem. Concr. Compos. 2012, 34, 1187-1193. [CrossRef]

47. Diamond, S. Mercury porosimetry. Cem. Concr. Res. 2000, 30, 1517-1525. [CrossRef]

48. Ortega, J.M.; Albaladejo, A.; Pastor, J.L.; Sánchez, I.; Climent, M.A. Influence of using slag cement on the microstructure and durability related properties of cement grouts for micropiles. Constr. Build. Mater. 2013, 38, 84-93. [CrossRef]

49. Wolsiefer, J.T. Silica fume concrete: A solution to steel reinforcement corrosion in concrete. In Utilization of Industrial By-Products for Construction Materials; ASCE: Reston, VA, USA, 1993; pp. 15-29.

50. Dotto, J.M.R.; Abreu, A.G.D.; Dal Molin, D.C.C.; Müller, I.L. Influence of silica fume addition on concretes physical properties and on corrosion behaviour of reinforcement bars. Cem. Concr. Compos. 2004, 26, 31-39. [CrossRef]

51. Tumidajski, P.J. Relationship between resistivity, diffusivity and microstructural descriptors for mortars with silica fume. Cem. Concr. Res. 2005, 35, 1262-1268. [CrossRef]

52. Delagrave, A.; Marchand, J.; Pigeon, M. Influence of Microstructure on the Tritiated Water Diffusivity of Mortars. Adv. Cem. Based Mater. 1998, 7, 60-65. [CrossRef]

53. Kunther, W.; Lothenbach, B.; Scrivener, K.L. Deterioration of mortar bars immersed in magnesium containing sulfate solutions. Mater. Struct. 2013, 46, 2003-2011. [CrossRef] 